\title{
Exercício pelo enfermeiro da advocacia em saúde em defesa do paciente: revisão
}

\section{integrativa}

\author{
Exercise by the health advocacy nurse in patient defense: integrative review \\ Ejercicio de la enfermera de defensa del paciente: revisión integrativa
}

Recebido: 01/08/2021 | Revisado: 11/08/2021 | Aceito: 15/08/2021 | Publicado: 17/08/2021

\author{
André Silveira Ito \\ ORCID: https://orcid.org/0000-0002-1245-1605 \\ Universidade Federal de Alfenas, Brasil \\ E-mail: andre.ito@sou.unifal-mg.edu.br \\ Maria Betânia Tinti de Andrade \\ ORCID: https://orcid.org/0000-0003-0329-1299 \\ Universidade Federal de Alfenas, Brasil \\ E-mail: betania.andrade@unifal-mg.edu.br \\ Eliana Peres Rocha Carvalho Leite \\ ORCID: https://orcid.org/0000-0002-4506-8899 \\ Universidade Federal de Alfenas, Brasil \\ E-mail: eliana.leite@unifal-mg.edu.br \\ Fábio de Souza Terra \\ ORCID: https://orcid.org/0000-0001-8322-3039 \\ Universal Federal de Alfenas, Brasil \\ E-mail: fabio.terra@unifal-mg.edu.br \\ Cristiane Aparecida Silveira-Monteiro \\ ORCID: https://orcid.org/0000-0002-8427-7220 \\ Universidade Federal de Alfenas, Brasil \\ E-mail: cristiane.monteiro@unifal-mg.edu.br
}

\begin{abstract}
Resumo
O termo advocacia em saúde pela enfermagem é definido como o apoio ativo do enfermeiro em relação aos direitos e escolhas do paciente, também como esclarecer suas decisões de assistência médica com auxílio na escolha de decisões informadas e protegendo os direitos humanos. O objetivo do presente artigo é analisar, na literatura nacional e internacional, o exercício de advocacia em saúde em defesa do paciente por enfermeiros. Trata-se de uma revisão da literatura realizada de março a julho de 2021 por meio da busca de estudos publicados de 2010 a 2020 em periódicos indexados no PubMed/MEDLINE, LILACS e CINAHL. A amostra foi composta por catorze estudos primários, principalmente em inglês e realizados no Brasil, EUA, Austrália, Suécia, Iran e Japão. Os artigos que compuseram a amostra do estudo podem ser sistematizados e apresentados a partir das categorias "Identificação de vulnerabilidades do direito do paciente" e "Comunicação com os pacientes, familiares e outros profissionais". Os enfermeiros estão advogando frente a ações que podem ser caracterizadas como identificação, comunicação para defender os direitos do paciente e enfrentando barreiras. Torna-se indispensável uma definição mais clara sobre advocacia em saúde pelo enfermeiro, como também mais estudos analisando a prática do exercício.
\end{abstract}

Palavras-chave: Defesa do paciente; Direito à saúde; Enfermagem; Revisão.

\begin{abstract}
The term health advocacy by nursing is defined as the active support of nurses in relation to the patient's rights and choices, as well as clarifying their healthcare decisions with assistance in choosing informed decisions and protecting human rights. The aim of this article is to analyze, in the national and international literature, the practice of health advocacy in patient defense by nurses. This is an integrative review conducted from March to July 2021 through the search for studies published from 2010 to 2020 in journals indexed in PubMed/MEDLINE, LILACS and CINAHL. The sample consisted of fourteen primary studies, mainly in English and conducted in Brazil, USA, Australia, Sweden, Iran and Japan. The articles that made up the study sample can be systematized and presented from the categories "Identification of vulnerabilities of law of the patient" and "Communication with patients, family members and other professionals". The nurses are advocating against actions that can be characterized as identification, communication to defend the patient's rights and facing barriers. a clearer definition of health advocacy by nurses is essential, as well as more studies analyzing the practice of exercise.
\end{abstract}

Keywords: Patient defense; Right to health; Nursing; Revision. 


\begin{abstract}
Resumen
El término defensa de la salud por parte de la enfermería se define como el apoyo activo de las enfermeras en relación con los derechos y las opciones de los pacientes, así como el esclarecimiento de sus decisiones de atención médica con asistencia para elegir decisiones informadas y proteger los derechos humanos. El objetivo de este artículo es analizar, en la literatura nacional e internacional, la práctica de la abogacía en salud en la defensa del paciente por parte del enfermero. Se trata de una revisión integradora realizada de marzo a julio de 2021 mediante la búsqueda de estudios publicados de 2010 a 2020 en revistas indexadas en PubMed / MEDLINE, LILACS y CINAHL. La muestra estuvo conformada por catorce estudios primarios, principalmente en inglés y realizados en Brasil, Estados Unidos, Australia, Suecia, Irán y Japón. Los artículos que conformaron la muestra de estudio pueden ser sistematizados y presentados a partir de las categorías "Identificación de vulnerabilidades de derecho del paciente" y "Comunicación con pacientes, familiares y otros profesionales". Los enfermeros están abogando por acciones que se pueden caracterizar como identificación, comunicación para defender los derechos del paciente y enfrentamiento de barreras. una definición más clara de la defensa de la salud. por enfermeras es fundamental, así como más estudios que analicen la práctica del ejercicio.
\end{abstract}

Palabras clave: Defensa del paciente; Derecho a la salud; Enfermería; Revisión.

\title{
1. Introdução
}

Etimologicamente, o termo advocatus tem origem no latim e significa aquele que intercede, defende ou julga a outra pessoa (Vaartio et al., 2009), enquanto advocacia tem sua origem no inglês advocacy, advindo da democracia norte-americana, tem como significado ações individuais e coletivas que procuram conscientizar as autoridades sobre as necessidades e carências que surgem na sociedade (Knitzer, 1976).

As definições tradicionais de advocacia surgiram a partir da profissão legal em que os direitos de uma pessoa são defendidos, assim como a sua causa. A necessidade de advogar para um paciente está intimamente relacionada com o nível de autonomia que este possa ter (Cole et al., 2014).

No âmbito da enfermagem a advocacia em saúde é discutida desde 1973 quando o Conselho Internacional de Enfermeiros introduziu o Código de Ética da profissão, que define que a enfermagem depende do respeito aos direitos humanos para exercer a sua atividade (Hamric et al., 2012; Hanks, 2010b). Na década seguinte, a discussão acerca da advocacia em saúde teve maior notoriedade, no entanto observa-se que a interpretação de alguns conceitos dentro da advocacia em saúde são discordantes até os dias atuais (Hamric et al., 2012).

A enfermagem passa a maior parte da sua carga horária de trabalho em contato com o paciente e usuário do serviço, sendo assim, está em melhor disposição para advogar devido ao conhecimento maior do quadro de saúde dos indivíduos e a continuidade do cuidado (Vaartio et al., 2009).

Existem algumas definições de advocacia usadas em enfermagem como, por exemplo, agir ou interceder no melhor interesse do paciente até a proteção dos seus direitos para garantir conforto e proteção aos incapazes de se comunicar, uma vez que a advocacia tem como base o cuidado, prática característica e essencial na enfermagem (Spence, 2011).

Entretanto, na área da saúde o termo possui diversas definições (Cole et al., 2014) e essas diversas interpretações da advocacia em saúde acarretam uma análise difícil da atuação do enfermeiro como defensor do paciente (Spence, 2011).

Como finalidade desse estudo, o termo advocacia em saúde pela enfermagem é definido como o apoio ativo do enfermeiro em relação aos direitos e escolhas do paciente, bem como o auxílio de decisões informadas e a proteção de seus direitos (Spence, 2011).

As percepções dos enfermeiros no tocante ao exercício da advocacia em saúde percorrem o senso de responsabilidade profissional ao formar uma relação adequada com os pacientes, como também os possíveis confrontos com os interesses da instituição, contribuindo para que exerçam sua autonomia na tomada de decisões ao informá-los sobre seus direitos (Hanks, 2010a).

O conceito de advocacia em defesa dos pacientes dentro da prática de enfermagem, mesmo que inconscientemente, está situada na formação educacional dos enfermeiros e nas tradições filosóficas da enfermagem (Cole et al., 2014), sendo que, 
na profissão a atuação em advocacia tem se mostrado evidente na prática da enfermagem (Hanks et al., 2018) devido ao elemento intrínseco da ética profissional, a defesa do paciente (Barlem et al., 2013).

$\mathrm{Na}$ oncologia, o exercício de advocacia pelos enfermeiros pauta-se na necessidade da comunicação, educação, apoio e reconhecimento da necessidade para intervir quando necessário, considerando a ética como guia para auxiliar na tomada de decisões, reforçando a necessidade de reflexões sobre a temática fortalecendo e embasando tecnicamente a prática profissional (Neves et al., 2020).

Uma das maiores responsabilidade do enfermeiro na Estratégia Saúde da Família (ESF) é atuar em ações diferentes na formulação, pactuação, monitoramento e avaliação de políticas que advêm sobre o cuidado, à melhoria da qualidade de vida das comunidades e os serviços de saúde (Pinto et al., 2017). Ao atuar em interesse da melhoria da qualidade de vida da comunidade na ESF, o enfermeiro também advoga pela saúde dos usuários, com incentivo ao empoderamento enquanto seres autônomos responsáveis por sua saúde. O enfermeiro, quando capacitado dos saberes científicos, de relacionamento e técnicos, e também o suporte de outros profissionais no trabalho, desenvolve sua autonomia na tomada de decisões, possuindo competência para desenvolver ações de advocacia em saúde para os usuários, sendo assim, qualifica o cuidado prestado (Figueira et al., 2018).

Apesar de haver pesquisas acerca da atuação em advocacia em saúde, há ainda divergências de definições propostas para o exercício, assim abrindo diversas interpretações por parte dos enfermeiros e influenciando em como ele atua ao defender o paciente (Bu \& Jezewski, 2007) devido às ações não apresentarem de forma estática e fixa, mas por particularidades de características do enfermeiro, influência de organizações e relações e de modo específico nos ambientes e situações (Simmonds, 2008).

Com a falta de uma definição clara e universal, estudos vêm propondo o conceito de advocacia em saúde a partir da atuação dos enfermeiros como defensor do paciente, em diferentes contextos, áreas de exercício ou culturas (Hanks, 2008; Negarandeh et al., 2006). No entanto, no contexto brasileiro, poucas pesquisas foram encontradas acerca da atuação em advocacia em saúde pelos enfermeiros (Tomaschewski-Barlem et al., 2015).

Também, há estudos que referem a advocacia em saúde pelo enfermeiro de um modo dificultoso e por vezes ausente devido a fatores de educação, compreensão do significado, cultura, religião e retaliação (Mortell, 2018).

Outra revisão acerca deste tema foi encontrada, no entanto, faz-se justificável a construção e desenvolvimento deste estudo devido à importância acerca da advocacia em saúde em defesa do paciente no cenário atual. Com isso, a presente pesquisa justifica-se na necessidade de análises de como os enfermeiros esteve exercendo a advocacia em saúde para o paciente, com o intuito de contribuir para uma melhor definição do seu papel e de suas ações frente à defesa do paciente.

Diante do exposto, o objetivo do presente estudo foi analisar, na literatura nacional e internacional, como os enfermeiros estão exercendo a advocacia em saúde em defesa do paciente.

\section{Metodologia}

Definiu-se como método a Revisão Integrativa (RI) de literatura que tem como objetivo agrupar e sintetizar os estudos realizados sobre determinado tema, para estabelecer conclusões a partir dos resultados, chegar a uma definição ou solução do problema levantado (Polit \& Beck, 2018).

A RI é o tipo de abordagem metodológica mais ampla no que se refere às revisões, o que possibilita a inclusão de estudos experimentais e não experimentais para a compreensão integral do fenômeno investigado (Whittemore \& Knafl, 2005).

Tal método é caracterizado por apresentar ampla abordagem metodológica referente às revisões, incluindo estudos com diferentes delineamentos de pesquisa para ampliar a compreensão. Na enfermagem, tem sido utilizada nas últimas décadas na tentativa de compreender o cuidado em saúde, nos âmbitos individual ou coletivo (Soares et al., 2014). 
Para este estudo, seguir-se-á a proposta delimitada por Mendes et al. (2008) que inclui seis etapas percorridas para a elaboração da RI: definição da pergunta norteadora, estabelecimento de critérios de inclusão e exclusão com a busca na literatura, definição das informações a serem extraídas, avaliação dos estudos incluídos, interpretação dos resultados e síntese dos dados.

A construção da questão de pesquisa foi feita pelo formato PICO, proposto por Santos et al. (2007), o qual a letra P refere-se à população de interesse, I é a intervenção ou questão/área de interesse, C é comparação ou grupo e O é o resultado de interesse. As perguntas que utilizam a estratégia PICO resultam em uma pesquisa eficaz que produz as informações mais relevantes e economiza grande quantidade de tempo para sintetizar a melhor evidência dos estudos existentes na literatura.

A população refere-se aos enfermeiros (P); a área de interesse, advocacia em saúde (I), não houve grupo comparação (C), o desfecho refere-se à defesa do paciente $(\mathrm{O})$. Assim, elaborou-se a seguinte pergunta da investigação: "Como os enfermeiros estão exercendo a advocacia em saúde em defesa do paciente?"

Para a busca dos estudos primários, a internet foi utilizada para acessar as seguintes bases de dados: Medical Literature Analyses and Retrieval System Online (MEDLINE) via PubMed®; Latin American and Caribbean Health Science Literature Database (LILACS) e Cummulative Index to Nursing and Allied Health Literature (CINAHL).

Os descritores controlados Enfermagem/Nursing, Enfermeiras e Enfermeiros/Nurses, Defesa do Paciente/Patient Advocacy, Direito à Saúde/Right to Health, selecionados com base nos Descritores em Ciências da Saúde e Medical Subject Headings, foram combinados com o uso do operador booleano (AND), associando dois a dois dos descritores selecionados.

Após completar a busca por dois revisores independentes, todos os artigos foram exportados para programa Rayyan® QCRI e os artigos duplicados foram removidos. Os critérios de elegibilidade foram estabelecidos com base na questão de revisão. Assim, foram incluídos estudos primários que abordaram o exercício por enfermeiros da advocacia em saúde em defesa do paciente; publicados em português, espanhol e inglês no período de 2010 a 2020.

Os estudos excluídos foram aqueles que exploraram o exercício da advocacia em saúde por outros profissionais de saúde, seja de forma isolada ou juntamente com o enfermeiro ou aqueles que estudaram a defesa do paciente pelos familiares ou pelos próprios pacientes. Também foram excluídos tipos de publicação como editoriais, revisões de literatura, estudos de caso, resumos de conferências e capítulos de livros, cartas ao editor, comentários e similares.

A coleta e análise de dados do presente estudo foram realizadas entre março e maio de 2021. Para gerenciamento dos resultados foi utilizado o programa Rayyan® QCRI para seleção dos textos (Ouzzani et al., 2016). Este aplicativo otimiza o trabalho das revisões de literatura, o qual identifica o título, o resumo e a data de publicação dos textos carregados das bases de dados para que o pesquisador os analise. Assim, permite a inclusão ou a exclusão de cada texto, com possibilidade de incluir a justificativa, o que deixa a filtragem dos artigos mais organizada e válida para posterior análise.

Após a etapa de levantamento das publicações, realizou-se a leitura do título e do resumo das 6494 publicações pelos dois revisores, de forma independente, considerando os critérios de inclusão e exclusão definidos. Em seguida, foi realizada a leitura na íntegra das publicações, atentando-se novamente aos critérios de inclusão e exclusão. Essa etapa auxiliou na categorização das informações extraídas das publicações.

$\mathrm{O}$ instrumento, elaborado pelos pesquisadores, teve como finalidade a extração e a análise dos dados dos estudos incluídos, sendo composto pelos seguintes itens: (1) Autor, (2) Periódico (3) Ano de Publicação; (4) Idioma e país; (5) Tipo de estudo; (6) Objetivo; (7) Delineamento Amostral; (8) Delineamento Metodológico (9) Principais resultados e (10) Nível de evidência (Melnyk \& Fineout-Overholt, 2019). As etapas de extração e análise dos resultados dos estudos primários foram realizadas por dois revisores, que desenvolveram este trabalho de forma independente.

A classificação hierárquica das evidências é realizada em níveis. Nesse sentido, quanto mais alta a evidência estiver representada na pirâmide, maior será o impacto desta intervenção no efeito de saúde desejado (Melnyk \& Fineout-Overholt, 
2019). Para a avaliação dos estudos primários incluídos no presente estudo e identificação do nível de evidência, foi empregada a classificação de evidências proposta por Melnyk e Fineout-Overholt (2019), a qual determina o nível de evidência de acordo com a questão clínica utilizada em cada estudo.

Para a identificação do delineamento de pesquisa dos estudos primários incluídos nesta RI, foi adotada nomenclatura utilizada pelos próprios autores dos estudos. Quando os autores não identificaram o tipo da pesquisa, a análise do delineamento foi fundamentada nos conceitos descritos por Polit e Beck (2018).

A análise e a síntese dos dados possibilitam ao leitor a associação de cada estudo primário incluído na revisão integrativa. Desse modo, foram formulados quadros-síntese, para cada estudo, com o registro dos seguintes dados: título, autor(es), nome do periódico, ano de publicação, objetivo(s), delineamentos amostral e metodológico, principais resultados e nível de evidência.

A seguir, os estudos primários foram agrupados de acordo com categorias baseadas nas temáticas em comum, após a leitura na íntegra de cada estudo primário incluído, para facilitar a compreensão do leitor e posterior discussão.

Ao final, os resultados e a discussão dos dados foram apresentados de maneira descritiva com o intuito de possibilitar ao leitor a avaliação da aplicabilidade do método da RI elaborada, buscando atingir o objetivo deste estudo.

\section{Resultados}

A sistematização da seleção das publicações nas bases da literatura científica está apresentada em um fluxograma, com a descrição das etapas de busca com o quantitativo de publicações em cada uma das bases. Foram considerados os critérios de inclusão e exclusão das 11035 publicações, até chegar ao número final de 14 publicações selecionadas para a revisão (Figura $1)$. 
Figura 1 - Fluxograma do processo de seleção das publicações selecionadas para a Revisão Integrativa. Alfenas-MG, Brasil (2021).

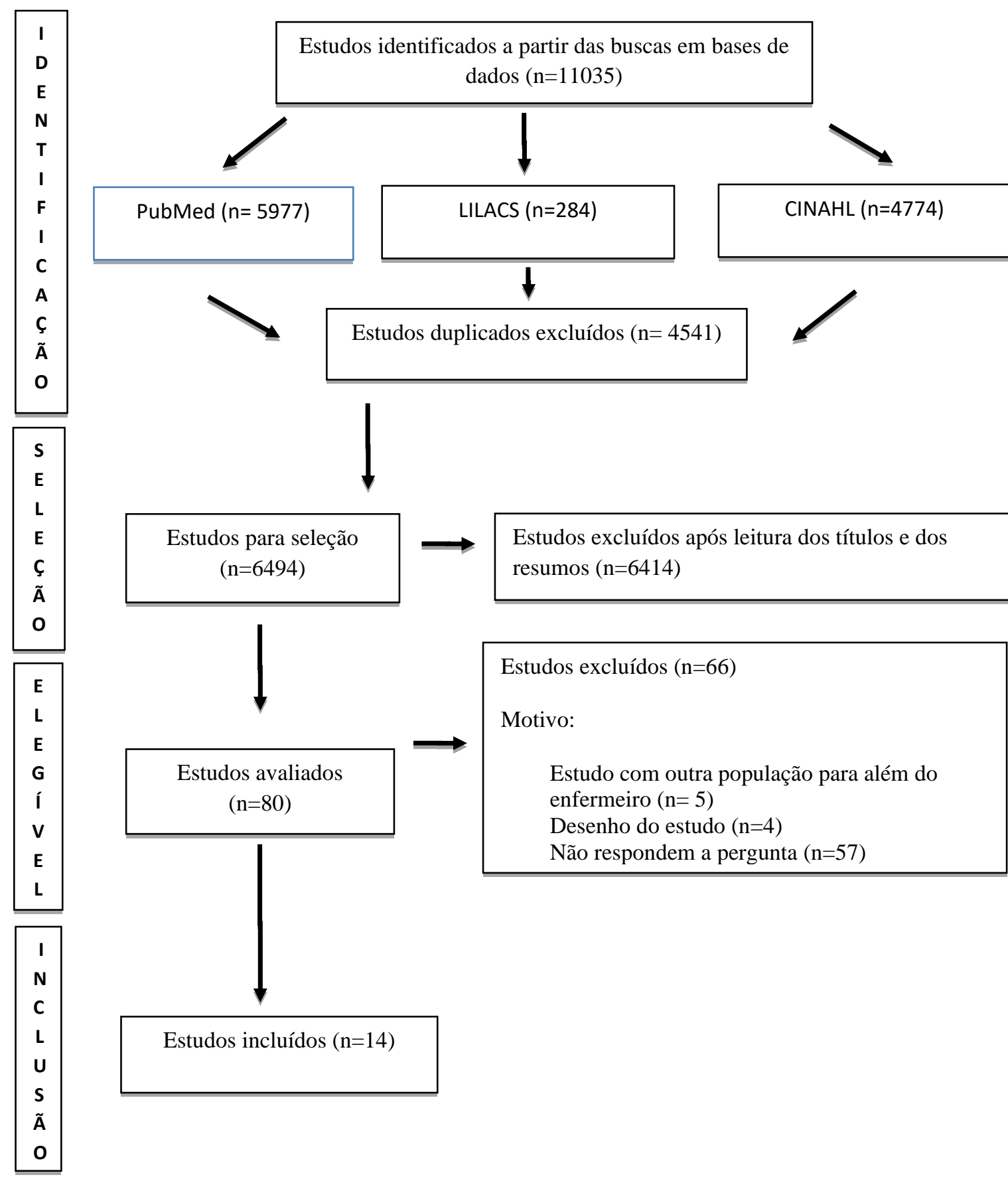

Fonte: Autores (2021)

Para a realização da análise de dados, foi construído dois quadros analíticos com informações extraídas dos estudos selecionados para avaliação das características gerais quanto a autor, periódico, idioma, país, questão clínica e nível de evidência (Quadro 1) e específicas que referem ao objetivo, detalhamento amostral, detalhamento metodológico e principais resultados (Quadro 2). 
Quadro 1 - Características gerais dos estudos incluídos na Revisão Integrativa. Alfenas-MG, Brasil (2021).

\begin{tabular}{|c|c|c|c|c|c|c|}
\hline $\mathbf{N}^{\mathbf{0}}$ & Autor & Periódico & Idioma & País & $\begin{array}{l}\text { Questão } \\
\text { clínica }\end{array}$ & $\begin{array}{l}\text { Nível de } \\
\text { evidência }\end{array}$ \\
\hline 1 & Andrade et al. (2013) & Ciência Cuidado e Saúde & Português & Brasil & Significado & II \\
\hline 2 & Andrade et al. (2015) & Texto \& Contexto-Enfermagem & Português & Brasil & Significado & II \\
\hline 3 & Black (2011) & American Journal of Nursing & Inglês & EUA & Prognóstico & IV \\
\hline 4 & Figueira et al. (2018) & $\begin{array}{l}\text { Revista da Escola de } \\
\text { Enfermagem da USP }\end{array}$ & Português & Brasil & Significado & IV \\
\hline 5 & Hanks (2010) & Nursing Forum & Inglês & EUA & Prognóstico & IV \\
\hline 6 & Luz et al. (2019) & Texto \& Contexto - Enfermagem & Português & Brasil & Prognóstico & IV \\
\hline 7 & $\begin{array}{l}\text { Negarandeh e Nayeri } \\
(2012)\end{array}$ & Indian Journal of Medical Ethics & Inglês & Irã & Significado & II \\
\hline 8 & $\begin{array}{l}\text { Reed, Fitzgerald e } \\
\text { Bish (2017) }\end{array}$ & Journal of Holistic Nursing & Inglês & Austrália & Intervenção & IV \\
\hline 9 & $\begin{array}{l}\text { Reed, Fitzgerald e } \\
\text { Bish (2018) }\end{array}$ & Rural and Remote Health & Inglês & Austrália & Prognóstico & IV \\
\hline 10 & $\begin{array}{l}\text { Sundqvist e Carlsson } \\
(2014)\end{array}$ & $\begin{array}{l}\text { Scandinavian Journal of Caring } \\
\text { Sciences }\end{array}$ & Inglês & Suécia & Significado & II \\
\hline 11 & $\begin{array}{l}\text { Sundqvist, Nilsson, } \\
\text { Holmefur e Andérzen- } \\
\text { Carlsson (2018) }\end{array}$ & Journal of Clinical Nursing & Inglês & Suécia & Prognóstico & IV \\
\hline 12 & Toda et al. (2015) & Nursing Ethics & Inglês & Japão & Prognóstico & IV \\
\hline 13 & $\begin{array}{l}\text { Tomaschewski- } \\
\text { Barlem et al. (2016) }\end{array}$ & Texto \& Contexto-Enfermagem & Português & Brasil & Prognóstico & IV \\
\hline 14 & Ware et al. (2011) & Pain Management Nursing & Inglês & EUA & Prognóstico & IV \\
\hline
\end{tabular}

Fonte: Autores (2021).

O Quadro 1 apresenta uma visão geral dos artigos incluídos de acordo com as características gerais: autor, idioma, país e nível de evidência. Os artigos incluídos foram realizados em diferentes países: Brasil (n= cinco), Estados Unidos da América ( $n=$ três), Austrália $(n=$ dois $)$, Suécia $(n=$ dois $)$, Irã $(n=u m)$, Japão $(n=u m)$; na língua inglesa $(n=$ nove $)$, portuguesa $(n=$ cin co). No que se refere ao tipo de questão clínica, oito estudos foram classificados como de Prognóstico/Predição ou Etiologia (nível IV, n=oito), cinco foram de Significado (nível II, n=quatro; nível IV, n=um) e um de Intervenção/Tratamento ou Diagnóstico/Teste Diagnóstico (nível VI, n=um). 
Quadro 2 - Características específicas dos estudos incluídos na Revisão Integrativa. Alfenas-MG, Brasil (2021).

\begin{tabular}{|c|c|c|c|c|}
\hline $\mathbf{N}^{\mathbf{o}}$ & Objetivo & $\begin{array}{l}\text { Detalhamento } \\
\text { Amostral }\end{array}$ & $\begin{array}{l}\text { Detalhamento } \\
\text { Metodológico }\end{array}$ & Principais resultados \\
\hline 1 & $\begin{array}{lrr}\text { Analisar } & \text { as } \\
\text { narrativas } & \text { dos } \\
\text { enfermeiros } & \text { sobre o } \\
\text { cuidado da } & \text { criança } \\
\text { na prática } & \text { de } \\
\text { puericultura, à } & \text { luz } \\
\text { do cuidado e } & \text { da } \\
\text { defesa do direito à } \\
\text { saúde. }\end{array}$ & $\begin{array}{lr}\text { Foram convidados } & 17 \\
\text { enfermeiros das ESF do } \\
\text { município de Passos- } \\
\text { MG, havendo recusa de } \\
\text { um e dois estavam de } \\
\text { licença-saúde. } & \text { A } \\
\text { amostra final } & \text { foi } \\
\text { composta por } & 14 \\
\text { enfermeiros, } & 12 \\
\text { mulheres e dois homens } \\
\text { atuantes na ESF. }\end{array}$ & $\begin{array}{l}\text { Estudo qualitativo } \\
\text { exploratório. Realizada } \\
\text { entrevista semiestruturada } \\
\text { sobre a prática cotidiana } \\
\text { dos enfermeiros na } \\
\text { puericultura. Analisado a } \\
\text { partir da análise de } \\
\text { conteúdo modalidade } \\
\text { temática. }\end{array}$ & $\begin{array}{l}\text { Foram elencados três temas: avaliação da criança, } \\
\text { identificação de situações vulneráveis para a criança e } \\
\text { dificuldades na abordagem e condução dos casos. Situações } \\
\text { em que abordagem se torna dificultosa e que o direito à saúde } \\
\text { da criança está em risco, deixam-nos inseguros e recorrem } \\
\text { para outros profissionais. No entanto, houve relato em que } \\
\text { essa solicitação de assistência por outro profissional, por vez } \\
\text { torna-se uma transferência de responsabilidade. Por análise, } \\
\text { evidencia-se a defesa dos direitos da criança por parte dos } \\
\text { enfermeiros das ESF, caracterizando suas ações de advocacia } \\
\text { e reafirmando a continuidade das suas ações e melhorias para } \\
\text { o desenvolvimento seguro e saudável da criança. }\end{array}$ \\
\hline 2 & $\begin{array}{l}\text { Identificar } \\
\text { elementos do } \\
\text { cuidado em favor da } \\
\text { infância na visita } \\
\text { domiciliária, a partir } \\
\text { de narrativas de } \\
\text { enfermeiros, na } \\
\text { perspectiva ro do } \\
\text { cuidado e da defesa } \\
\text { do direito à saúde da } \\
\text { criança. }\end{array}$ & $\begin{array}{lr}\text { Foram convidados } 17 \\
\text { enfermeiros das ESF do } \\
\text { município de Passos- } \\
\text { MG, havendo recusa de } \\
\text { um e dois estavam } \\
\text { licença-saúde. } & \text { A } \\
\text { amostra final } & \text { foi } \\
\text { composta por } & 14 \\
\text { enfermeiros, } & 12 \\
\text { mulheres e dois homens } \\
\text { atuantes na ESF. }\end{array}$ & 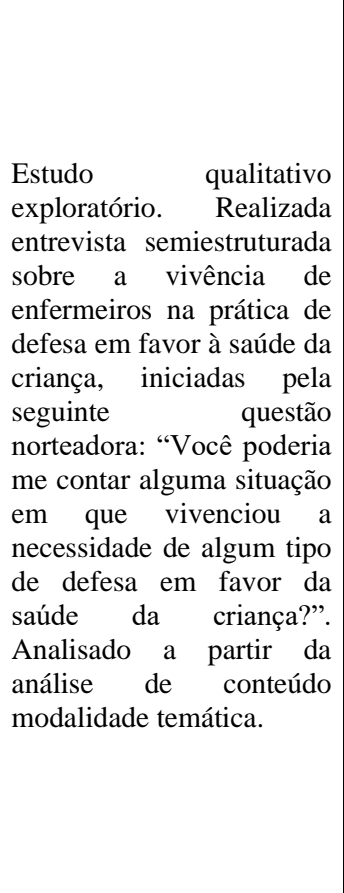 & $\begin{array}{l}\text { O estudo identificou e discutiu sobre os as ações e situações } \\
\text { dos enfermeiros acerca do cuidado com a criança na Visita } \\
\text { Domiciliar (VD). Foram elencados três temas: no primeiro, } \\
\text { observação e atenção para o cuidado da criança em casa, os } \\
\text { enfermeiros identificam a VD como um momento oportuno } \\
\text { para a atenção a criança, identificando suas necessidades, } \\
\text { vulnerabilidades, como também agindo de forma preventiva e } \\
\text { intermediadora para os demais profissionais. No segundo } \\
\text { tema, apreensão de situações de violação de direitos, os } \\
\text { entrevistados identificaram a VD como uma possibilidade de } \\
\text { avaliar as situações de vulnerabilidades que não são levadas } \\
\text { às consultas, como mudanças sociais, funcionamento familiar } \\
\text { e negligências. Foi relatado pelos entrevistados uma limitação } \\
\text { dessa ação investigativa uma vez que a família pode ocultar } \\
\text { esses comportamentos danosos à criança, gerando angústia } \\
\text { aos profissionais. Ao que se diz respeito do último tema, } \\
\text { vulnerabilidades na infância com pais usuários de álcool e } \\
\text { outras drogas, os enfermeiros compreendem a situação de } \\
\text { dependência química de familiares como risco à integralidade } \\
\text { da criança, comprometendo a parceria e a qualidade dos } \\
\text { cuidados dela e dificultando para o enfermeiro prover } \\
\text { segurança aos vulneráveis. Nessas ocasiões demanda ao } \\
\text { enfermeiro acionar outros setores, como assistência social e } \\
\text { justiça para apoiá-los a prover a segurança das crianças, em } \\
\text { vez que essas situações ultrapassam do âmbito de } \\
\text { exclusividade da prática dos enfermeiros. }\end{array}$ \\
\hline 3 & 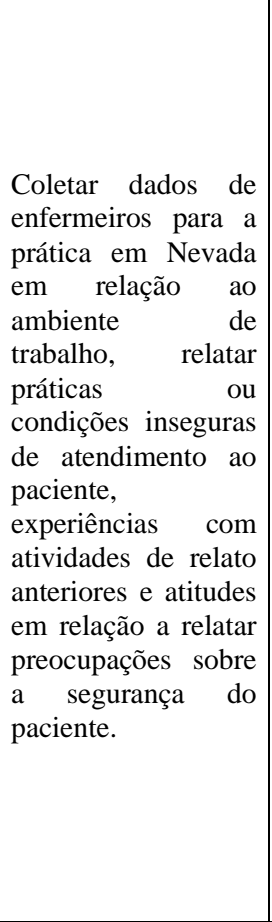 & $\begin{array}{l}\text { Uma amostra aleatória } \\
\text { de } 1.725 \text { enfermeiros, } \\
\text { representando } 10 \% \text { de } \\
\text { todos os enfermeiros } \\
\text { com licenças ativas e } \\
\text { endereços atuais de } \\
\text { Nevada/EUA. } \quad \text { A } \\
\text { pesquisa foi distribuída } \\
\text { pelo correio dos EUA; } \\
\text { os respondentes } \\
\text { poderiam completá-lo } \\
\text { online ou preenchendo e } \\
\text { devolvendo a pesquisa } \\
\text { em papel. }\end{array}$ & 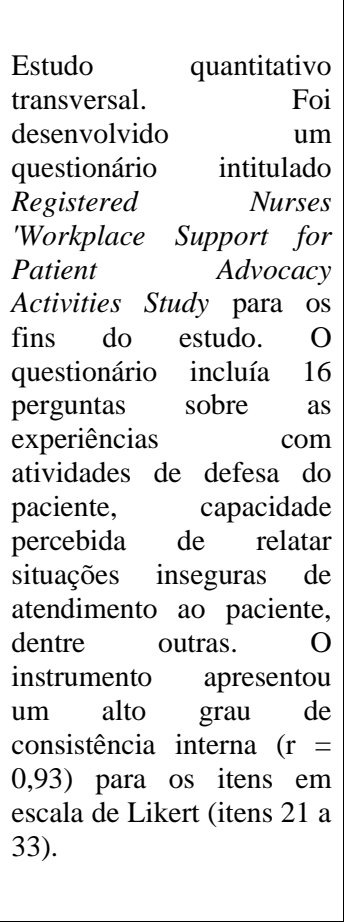 & $\begin{array}{l}\text { Um total de } 564 \text { respostas válidas foram recebidas, (taxa de } \\
\text { resposta de } 33 \% \text { ). O entrevistado médio tinha } 49 \text { anos, } \\
\text { trabalharam um pouco menos de } 38 \text { horas regulares } \\
\text { programadas e três horas extras não programadas a cada } \\
\text { semana. Noventa e um por cento (513) dos entrevistados eram } \\
\text { mulheres, } 79 \% \text { (448) identificados como brancos, } 72 \% \text { (403) } \\
\text { eram casados ou tinham companheiro (a), e pouco mais da } \\
\text { metade (322) tinha pelo menos um dependente morando em } \\
\text { sua casa. Quarenta por cento (223) dos entrevistados } \\
\text { relataram possuir certificação em sua especialidade de prática, } \\
31 \% \text { (173) relataram ser representados por um sindicato em } \\
\text { seu ambiente de trabalho. Enquanto } 73 \% \text { (412) dos } \\
\text { entrevistados afirmaram que já haviam relatado uma situação } \\
\text { insegura de atendimento ao paciente para pessoas que sentiam } \\
\text { que seriam capazes de corrigi-la, } 34 \% \text { (194) afirmaram ter } \\
\text { conhecimento de uma situação que poderia causar dano a um } \\
\text { paciente, mas não relataram; } 38 \% \text { dos enfermeiros } \\
\text { trabalhando em ambientes de cuidados agudos (134 de } 349 \\
\text { enfermeiras) e } 29 \% \text { enfermeiras que trabalham em ambientes } \\
\text { de cuidados não agudos (60 de } 210 \text { enfermeiras) responderam } \\
\text { que estavam cientes de uma situação insegura de atendimento } \\
\text { ao paciente que não foi relatada. Os entrevistados que } \\
\text { estavam cientes de uma situação insegura de atendimento ao } \\
\text { paciente e não relataram foram solicitados a "escolher o } \\
\text { motivo mais importante pelo qual você não relatou essa } \\
\text { preocupação". Dos que responderam, } 44 \% \text { (79) indicaram que } \\
\text { estavam preocupados em sofrer retaliação por ter feito uma }\end{array}$ \\
\hline
\end{tabular}




\begin{tabular}{|c|c|c|c|c|}
\hline & & & & $\begin{array}{l}\text { denúncia, enquanto } 38 \% \text { (68) relataram que não achavam que } \\
\text { nada sairia da denúncia. Menos enfermeiras indicaram que } \\
\text { não sabiam como ou a quem relatar a situação, não tinham } \\
\text { tempo para relatar ou sentiam que a situação "não era da } \\
\text { minha conta". Sessenta e um por cento (342) sentiram que } \\
\text { poderiam relatar uma preocupação com a segurança do } \\
\text { paciente sem sofrer retaliação no local de trabalho. Mas } \\
\text { muitos entrevistados indicaram ter experimentado tal } \\
\text { retaliação por relatar as ações de uma enfermeira (18\%; 88) } \\
\text { ou de um médico (15\%; 76); } 41 \% \text { (230) indicaram que } \\
\text { conheciam ou sabiam de uma enfermeira que havia sofrido } \\
\text { retaliação no local de trabalho após relatar as ações de outra } \\
\text { enfermeira da equipe. Quase um terço dos entrevistados } \\
\text { conhecia ou conhecia uma enfermeira que havia sofrido } \\
\text { retaliação no local de trabalho por relatar as ações de um } \\
\text { supervisor de enfermagem (30\%; 170) ou de um médico } \\
\text { (30\%; } 167) \text {. 62\% dos entrevistados (142) que conheciam uma } \\
\text { enfermeira que sofreu retaliação por relatar as ações de outra } \\
\text { enfermeira indicaram que estavam cientes de uma } \\
\text { preocupação com a segurança do paciente, mas não a } \\
\text { relataram. Embora a maioria dos enfermeiros pesquisados } \\
\text { estivesse satisfeita com sua posição atual de enfermagem } \\
\text { (71\%; } 398) \text { e com a enfermagem como carreira (75\%; } 423) \text {, } \\
\text { havia uma relação muito forte entre o nível de satisfação de } \\
\text { um enfermeiro com sua enfermagem posição e a } \\
\text { probabilidade de ela relatar uma preocupação com a } \\
\text { segurança do paciente (F = } 128,4 ; \text { P }<0,001) \text {. Das enfermeiras } \\
\text { que concordaram fortemente com a afirmação "Estou } \\
\text { satisfeito com minha posição atual de enfermagem", apenas } \\
15 \% \text { (25) indicaram que estavam cientes de uma preocupação } \\
\text { com a segurança do paciente e não a relataram. No entanto, } \\
\text { daqueles que discordaram veementemente da afirmação, } 72 \% \\
(28) \text { tinham conhecimento de uma preocupação com a } \\
\text { segurança do paciente e não a relataram. }\end{array}$ \\
\hline 4 & $\begin{array}{lr}\text { Conhecer as ações } \\
\text { de advocacia } \\
\text { saúde em } \\
\text { empoderamento dos } \\
\text { usuários } \\
\text { desenvolvidos } \\
\text { enfermeiros por } \\
\text { Estratégia Saúde da } \\
\text { Família no Brasil. }\end{array}$ & 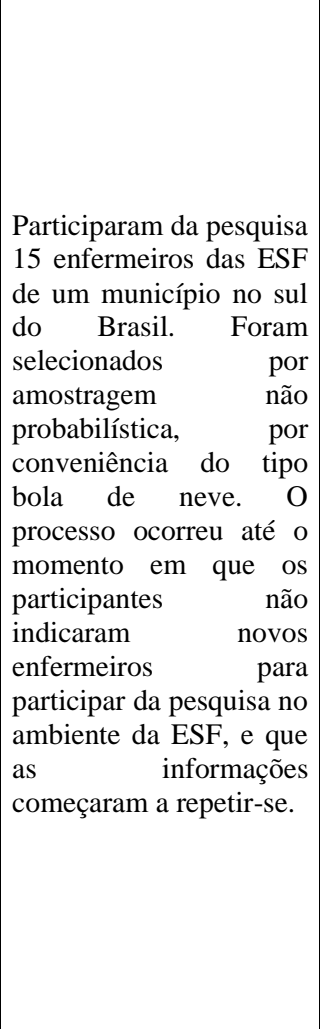 & 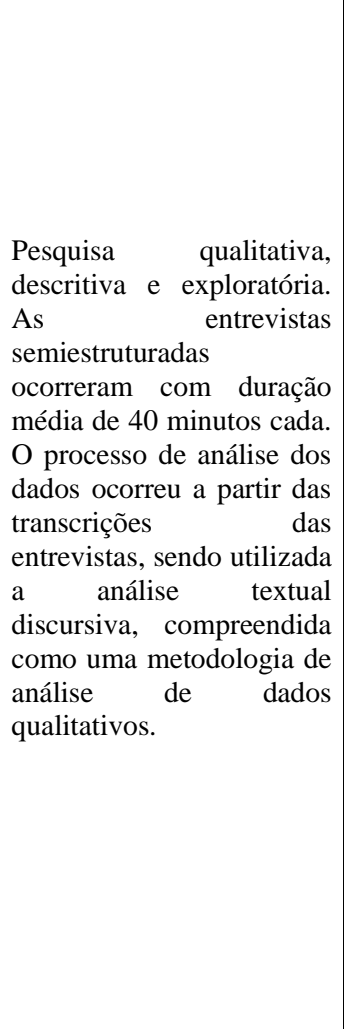 & $\begin{array}{l}\text { Foram elencadas três categorias: na primeira, participação dos } \\
\text { usuários, identificado elementos constitutivos como a troca de } \\
\text { saberes, a educação em saúde, a realização de grupos, as VD e } \\
\text { as consultas de enfermagem. Apesar destes elementos serem } \\
\text { função normativa dos enfermeiros, a implicação deles faz com } \\
\text { que a defesa e o empoderamento do paciente sejam exercidos. } \\
\text { Foi apontado que para a participação do usuário seja efetiva, o } \\
\text { enfermeiro deve ter um bom exercício do diálogo com o } \\
\text { paciente dentro dos elementos citados. Na segunda categoria, } \\
\text { ambiente de saúde, os entrevistados caracterizam as ações } \\
\text { ambientais e locais, tanto a rotina da ESF como também as } \\
\text { ações exercidas fora da unidade. Dentro dessas ações, os } \\
\text { entrevistados relatam a importância do reconhecimento da } \\
\text { comunidade em que a ESF está inserida, sua população e seus } \\
\text { grupos específicos assim como os locais de implementações } \\
\text { de saúde para que possam adotar estratégias visando a } \\
\text { comunidade que ali irá usufruir da unidade. Também se } \\
\text { identifica a importância da advocacia política para a defesa de } \\
\text { políticas públicas que afetam a comunidade, a necessidade de, } \\
\text { além dos enfermeiros a população também reivindicar seus } \\
\text { direitos quanto a políticas públicas. Na última categoria, ações } \\
\text { de advocacia em saúde relacionadas à equipe } \\
\text { multiprofissional, é relatada pelos entrevistados a relação } \\
\text { deles com o resto da equipe que compõe a ESF, sendo a } \\
\text { constante troca de saberes com o bom conhecimento clínico } \\
\text { dos profissionais essencial para a manutenção da qualidade de } \\
\text { cuidados adequados e a disseminação de informações para os } \\
\text { pacientes. Identificou-se a articulação dos enfermeiros das } \\
\text { ESF em suas ações de advocacia que favorece a saúde e o } \\
\text { empoderamento dos usuários. }\end{array}$ \\
\hline 5 & $\begin{array}{l}\text { Explorar as ações de } \\
\text { defesa de } \\
\text { enfermagem e apoio } \\
\text { no local de trabalho } \\
\text { para defesa de } \\
\text { direitos usando }\end{array}$ & $\begin{array}{l}\text { Os convites foram } \\
\text { enviados via mala-direta } \\
\text { a } 5.000 \text { enfermeiras } \\
\text { médico-cirúrgicas auto- } \\
\text { identificadas no Texas } \\
\text { Board of Nursing. }\end{array}$ & $\begin{array}{l}\text { Pesquisa descritiva mista. } \\
\text { Os participantes foram } \\
\text { solicitados a responder a } \\
\text { três perguntas: } 1 \text { ) "Quando } \\
\text { estou agindo como um } \\
\text { advogado para meu (s) }\end{array}$ & $\begin{array}{l}\text { A maioria dos participantes era do sexo feminino }(90,3 \%) \text {, } \\
\text { branca }(69 \%), 87,8 \% \text { possuíam experiência em tempo integral } \\
\text { na enfermagem médico-cirúrgica, trabalhavam em tempo } \\
\text { integral }(81,5 \%) \text {, com média de } 14,05 \text { anos na enfermagem } \\
\text { médico-cirúrgica; } 86,6 \% \text { trabalhavam em ambiente hospitalar. } \\
\text { Em relação a primeira questão: as ações mais frequentes que }\end{array}$ \\
\hline
\end{tabular}




\begin{tabular}{|c|c|c|c|c|}
\hline & $\begin{array}{l}\text { respostas narrativas } \\
\text { escritas a uma } \\
\text { pesquisa enviada } \\
\text { por correio usando } \\
\text { uma amostra de } \\
\text { enfermagem } \\
\text { médico-cirúrgica. }\end{array}$ & $\begin{array}{l}\text { Critérios de inclusão: (a) } \\
1 \text { ano de experiência em } \\
\text { tempo integral (ou } \\
\text { equivalente a tempo } \\
\text { parcial) na especialidade } \\
\text { médico-cirúrgica em } \\
\text { cuidados intensivos; e } \\
\text { (b) reconhecimento para } \\
\text { exercer a profissão de } \\
\text { enfermeira registrada. } \\
\text { Critérios de exclusão: } \\
\text { (a) equipe re de } \\
\text { enfermagem r não } \\
\text { reconhecida como } \\
\text { enfermeira profissional } \\
\text { registrada no Estado do } \\
\text { Texas; (b) menos de } 1 \\
\text { ano de experiência em } \\
\text { tempo integral (ou o } \\
\text { equivalente em tempo } \\
\text { parcial) na área de } \\
\text { especialidade médico- } \\
\text { cirúrgica trabalhando } \\
\text { como enfermeira } \\
\text { profissional registrada. }\end{array}$ & $\begin{array}{l}\text { paciente (s), estou } \\
\text { realizando as seguintes } \\
\text { ações"; 2) "Quando estou } \\
\text { atuando como defensor do } \\
\text { (s) meu (s) paciente (s), o } \\
\text { apoio para a defesa do } \\
\text { paciente em meu local de } \\
\text { trabalho pode ser descrito } \\
\text { como..."; 3)"Quando estou } \\
\text { agindo como advogado de } \\
\text { meus pacientes, garanto } \\
\text { que estou seguindo os } \\
\text { desejos do paciente..." As } \\
\text { respostas narrativas foram } \\
\text { analisadas usando um } \\
\text { projeto de análise de } \\
\text { conteúdo quantitativo, } \\
\text { conforme descrito por } \\
\text { Weber (1990). }\end{array}$ & $\begin{array}{l}\text { as enfermeiras indicaram que realizavam como advogadas } \\
\text { foram educar o paciente e família, seguida da comunicação } \\
\text { com os demais membros da equipe de saúde. Outras açôes } \\
\text { significativas incluíram: (a) questionar e garantir o cuidado } \\
\text { adequado, (b) avaliar os desejos do paciente, (c) comunicar-se } \\
\text { com o paciente e sua família, (d) garantir a segurança, (e) } \\
\text { respeitar e proteger os direitos do paciente, e (f) falar e agir } \\
\text { em nome do paciente. Em relação à segunda pergunta sobre o } \\
\text { apoio no local de trabalho para as ações de advocacia a } \\
\text { maioria foi: (a) positiva, (b) ruim, (c) razoável e (d) excelente } \\
\text { suporte para a defesa do paciente do enfermeiro. A última } \\
\text { questão relativa a seguir os desejos do paciente enquanto agia } \\
\text { como advogado de enfermagem: (a) interagir e comunicar-se } \\
\text { com o paciente e família, (b) avaliar e revisar os desejos, (c) } \\
\text { agir de acordo com os desejos do paciente, (d) interagir e } \\
\text { comunicar com outros profissionais de saúde, e (e) diretivas } \\
\text { antecipadas. Categorias adicionais com mais de } 10 \text { contagens } \\
\text { de frequência incluíram educação, cuidados adequados e } \\
\text { documentação. Todas as três perguntas narrativas foram } \\
\text { apresentadas com uma ampla variedade de respostas, o que } \\
\text { provavelmente reflete as perguntas abertas. Os participantes } \\
\text { podem ter interpretado as questões abertas de forma diferente } \\
\text { em relação às suas próprias experiências com a advocacia de } \\
\text { enfermagem e isso pode explicar o alto grau de variação nas } \\
\text { categorias. }\end{array}$ \\
\hline 6 & $\begin{array}{lr}\text { Analisar } & \text { como } \\
\text { enfermeiros } & \\
\text { intensivistas } & \text { têm } \\
\text { exercido } & \mathrm{a} \\
\text { advocacia } & \text { do } \\
\text { paciente diante } & \text { da } \\
\text { necessidade } & \text { de } \\
\text { internação } & \text { em } \\
\text { unidade de terapia } \\
\text { intensiva por ordem } \\
\text { judicial, perante } \\
\text { in/viabilidade de } \\
\text { leito. }\end{array}$ & $\begin{array}{l}\text { Foram selecionados } 42 \\
\text { enfermeiros intensivistas } \\
\text { das regiões sul e sudeste } \\
\text { do Brasil, mediante } \\
\text { amostragem por bola de } \\
\text { neve. Critérios de } \\
\text { inclusão: ser enfermeiro, } \\
\text { desenvolver atividade } \\
\text { assistencial na terapia } \\
\text { intensiva adulto, não se } \\
\text { encontrar em férias, } \\
\text { afastamento ou licença, } \\
\text { possuir um ano ou mais } \\
\text { de experiência na terapia } \\
\text { intensiva e que tenham } \\
\text { vivenciado a experiência } \\
\text { da internação por ordem } \\
\text { judicial. }\end{array}$ & 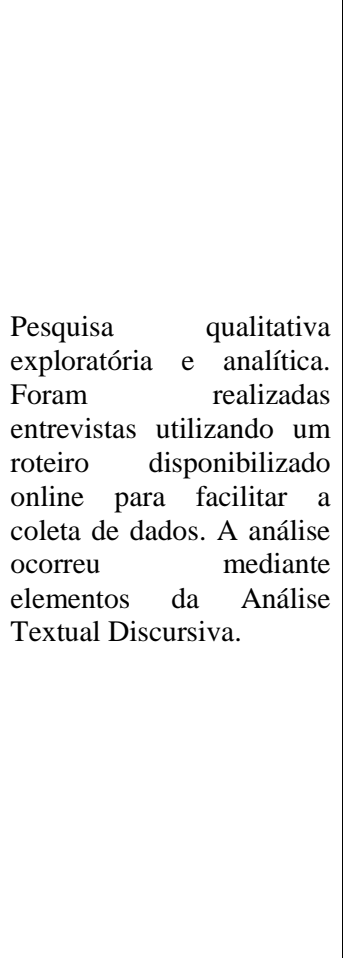 & $\begin{array}{l}\text { Foram elencadas duas categorias a partir da análise, sendo a } \\
\text { primeira, "a posição dos enfermeiros no exercício da } \\
\text { advocacia do paciente que necessita de leito na terapia } \\
\text { intensiva", as barreiras para exercer advocacia perante o } \\
\text { paciente que está internado por ordem judicial, em que este } \\
\text { papel depende muitas vezes de fatores externos } \\
\text { inquestionáveis por eles. Relatam que em ocasiões os médicos } \\
\text { ficam à frente das decisões e inviabilizando o } \\
\text { compartilhamento das responsabilidades, dificultando o } \\
\text { processo de advogar pelo paciente e tornando a situação } \\
\text { estressante. Também ressaltam que a solicitação de leitos é } \\
\text { um processo antigo, dependendo de fatores políticos e } \\
\text { institucionais que são de difícil manejo. Já na segunda } \\
\text { categoria, "A posição dos enfermeiros no exercício da } \\
\text { advocacia do paciente que necessita de leito na terapia } \\
\text { intensiva" mostra as ações dos entrevistados através de } \\
\text { orientações direcionadas acerca dos direitos dos pacientes e } \\
\text { da proteção exercida para pacientes e familiares de } \\
\text { julgamentos da equipe multiprofissional que possam } \\
\text { comprometer seus direitos e o atendimento preconceituoso. } \\
\text { Identifica-se uma lacuna entre ideal e direito de defesa do } \\
\text { paciente na prática diária de enfermagem pela dificultosa } \\
\text { prática de advocacia perante a apreensão, decisões soberanas } \\
\text { e punição que eles estão submetidos. Entretanto, ainda que } \\
\text { subjugados pelo exercício, os enfermeiros prestam parte da } \\
\text { advocacia impedindo que os cuidados dos pacientes sejam de } \\
\text { forma humanizada ao mantê-los informados de seus direitos, } \\
\text { do processo de tratamento e situação do caso. }\end{array}$ \\
\hline 7 & $\begin{array}{l}\text { Investigar o } \\
\text { significado da } \\
\text { defesa do paciente a } \\
\text { partir da perspectiva } \\
\text { das enfermeiras } \\
\text { iranianas. }\end{array}$ & $\begin{array}{l}\text { Foram recrutadas } 24 \\
\text { enfermeiras que } \\
\text { trabalham em um grande } \\
\text { hospital universitário em } \\
\text { Teerã. Entrevistaram-se } \\
\text { três enfermeiras chefes, } \\
\text { três supervisores e } 18 \\
\text { enfermeiras. }\end{array}$ & $\begin{array}{l}\text { Estudo qualitativo do tipo } \\
\text { teoria fundamentada. Uma } \\
\text { estrutura qualitativa } \\
\text { usando os elementos dos } \\
\text { métodos de análise de } \\
\text { dados de Strauss e Corbin } \\
\text { foi considerada como o } \\
\text { método mais apropriado } \\
\text { de investigação. Foram } \\
\text { realizadas entrevistas } \\
\text { semiestruturadas } \\
\text { individuais. Cada } \\
\text { entrevista começou com } \\
\text { uma pergunta ampla, } \\
\text { como: Você poderia } \\
\text { descrever um de seus } \\
\text { turnos de trabalho? e, em }\end{array}$ & $\begin{array}{l}\text { A idade dos participantes variou de } 23 \text { a } 50 \text { anos (média } \\
33,45 \text { ). O tempo de prática de enfermagem variou de } 1 \text { a } 26 \\
\text { anos (média 10,59); } 23 \text { participantes possuíam o título de } \\
\text { bacharel em enfermagem e um, o mestrado em fisiologia. Os } \\
\text { temas que emergiram foram: informando e educando; } \\
\text { valorizar e respeitar; apoiar fisicamente, emocionalmente e } \\
\text { financeiramente; proteger e representar; promover a } \\
\text { continuidade do cuidado. } \\
\text { Informando e educando: Todos os participantes descreveram } \\
\text { informar e educar como uma forma de advogar pelos } \\
\text { pacientes, pois isso diminui o estresse e a preocupação dos } \\
\text { pacientes. Eles acreditavam que a consciência dos pacientes } \\
\text { sobre seu diagnóstico e outras questões relacionadas é um } \\
\text { direito. A educação também foi vista como um meio de } \\
\text { empoderar os clientes e suas famílias. Eles também } \\
\text { informaram os pacientes sobre problemas médicos e opções }\end{array}$ \\
\hline
\end{tabular}




\begin{tabular}{|c|c|c|c|c|}
\hline & & & $\begin{array}{l}\text { seguida, eles foram } \\
\text { solicitados a explicar suas } \\
\text { próprias experiências e } \\
\text { percepções de "defesa do } \\
\text { paciente", bem como o } \\
\text { que fizeram ao defender } \\
\text { um paciente. Os dados das } \\
\text { entrevistas } \\
\text { analisados pelo método } \\
\text { comparativo constante até } \\
\text { a saturação dos dados. A } \\
\text { análise dos dados } \\
\text { assemelha-se a uma } \\
\text { discussão entre os dados } \\
\text { reais, a teoria criada, os } \\
\text { memorandos e o } \\
\text { pesquisador. }\end{array}$ & $\begin{array}{l}\text { de tratamento, e os serviços disponíveis para ajudar os } \\
\text { pacientes e suas famílias, dentro e fora do hospital. } \\
\text { Valorizando e respeitando: Valor e respeito foram outros } \\
\text { componentes importantes da defesa percebida pelos } \\
\text { participantes. A maioria acredita que a advocacia ocorre se } \\
\text { mostrarmos respeito pela individualidade dos pacientes e sua } \\
\text { dignidade humana inerente, bem como a defesa dos direitos } \\
\text { do cliente, como privacidade, confidencialidade, atendimento } \\
\text { de saúde de qualidade e acesso a todos os serviços } \\
\text { hospitalares e comunitários disponíveis. As enfermeiras } \\
\text { também enfatizaram as relações de respeito com os pacientes } \\
\text { e consideraram imperativo estabelecer confiança. } \\
\text { Apoiar fisicamente, emocionalmente e financeiramente: o } \\
\text { apoio ao paciente pode ser físico, emocional ou financeiro e } \\
\text { pode melhorar tanto a saúde quanto o bem-estar. Enfatizavam } \\
\text { o conforto e o alívio da dor dos pacientes como um tipo de } \\
\text { defesa física. Ganhar a confiança da família e apoiá-la } \\
\text { emocionalmente também foi descrito pelos participantes. } \\
\text { Protegendo: Esta categoria inclui códigos como defesa, } \\
\text { intercessão, relatório, proteção, segurança e garantia de } \\
\text { privacidade. Todos os enfermeiros enfocaram a qualidade dos } \\
\text { cuidados e serviços como elementos-chave para uma } \\
\text { advocacia eficaz. Eles acreditavam que, quando a qualidade } \\
\text { do atendimento cai é necessário que os enfermeiros atuem } \\
\text { como seus defensores. } \\
\text { Promovendo cuidado contínuo: Os participantes descreveram } \\
\text { muitos casos em que a advocacia poderia promover a } \\
\text { continuidade do atendimento, acompanhamento e } \\
\text { coordenação. Por estar familiarizado com os diversos recursos } \\
\text { dentro e fora do hospital, o enfermeiro presta serviços como a } \\
\text { coordenação de procedimentos diagnósticos e terapêuticos. }\end{array}$ \\
\hline 8 & $\begin{array}{l}\text { Desenvolver um } \\
\text { modelo holístico de } \\
\text { prática de } \\
\text { enfermagem distrital } \\
\text { para informar a } \\
\text { defesa do fim da } \\
\text { vida centrada na } \\
\text { pessoa. }\end{array}$ & 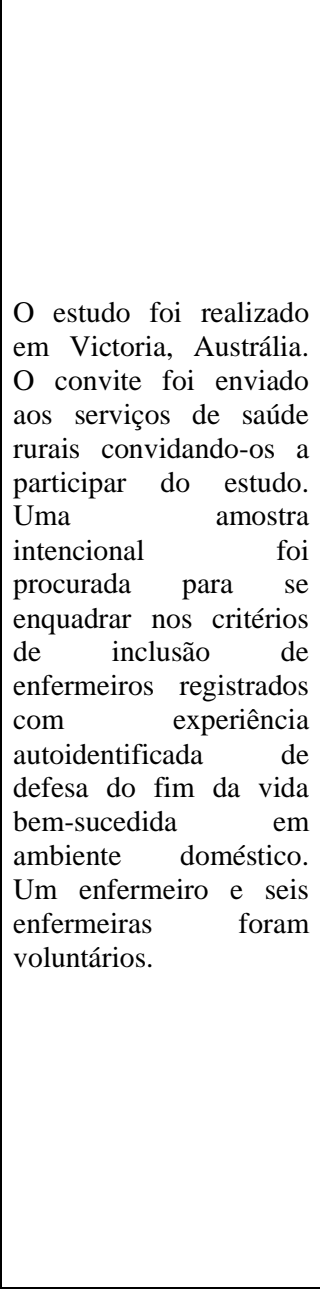 & $\begin{array}{l}\text { Pesquisa qualitativa. Foi } \\
\text { realizada uma entrevista } \\
\text { narrativa. Os enfermeiros } \\
\text { distritais foram } \\
\text { convidados a escrever } \\
\text { sobre uma experiência de } \\
\text { advocacia bem-sucedida } \\
\text { primeiro, para dar tempo } \\
\text { para reflexão sobre a } \\
\text { prática. Quando cada } \\
\text { experiência escrita era } \\
\text { devolvida, a pesquisadora } \\
\text { contatava o informante por } \\
\text { telefone para organizar a } \\
\text { segunda parte da coleta de } \\
\text { dados. A participação } \\
\text { individual em uma } \\
\text { entrevista de } 1 \text { hora em } \\
\text { profundidade foi arranjada } \\
\text { de acordo com a } \\
\text { conveniência do do } \\
\text { informante para ter acesso } \\
\text { subjetivo mais profundo e } \\
\text { significado dos tópicos. A } \\
\text { exploração da experiência } \\
\text { escrita e um guia de } \\
\text { entrevista semiestruturado } \\
\text { derivado da literatura } \\
\text { foram usados para facilitar } \\
\text { a continuidade e enfocar a } \\
\text { questão da pesquisa na } \\
\text { coleta de dados. Utilizou- } \\
\text { se as ferramentas de } \\
\text { mapeamento e consulta } \\
\text { fornecidas no programa } \\
\text { Nvivo QRS10 para indicar } \\
\text { vários relacionamentos de } \\
\text { conexão e níveis de }\end{array}$ & $\begin{array}{l}\text { Todos eram enfermeiros experientes, seis tinham pelo menos } \\
5 \text { anos em enfermagem distrital e um tinha uma certificação } \\
\text { de pós-graduação em cuidados paliativos. Os temas básicos } \\
\text { identificados constituem três temas de organização } \\
\text { interdependentes que contribuem para o tema global de } \\
\text { advocacia de sucesso: } \\
\text { Estar "disposto" a investir no cuidado centrado na pessoa } \\
\text { emergiu dos temas básicos de a) envolvimento (investimento } \\
\text { do próprio profissional e pessoal nas experiências das pessoas } \\
\text { e suas redes de apoio); b) energia emocional (Uma paixão } \\
\text { pelo "bom" na defesa de objetivos centrados na pessoa, } \\
\text { destaque nas narrativas de todos os informantes) e c) } \\
\text { autonomia (uma vantagem na ação de advocacia para poder } \\
\text { dar uma resposta oportuna). "Saber" como advogar como } \\
\text { enfermeira distrital emergiu dos temas básicos de (a) } \\
\text { conhecimento pessoal (conhecer as pessoas em sua própria } \\
\text { casa e nas circunstâncias sociais rurais) e (b) conhecimento } \\
\text { dos recursos de saúde e da comunidade (conhecimento de } \\
\text { uma ampla variedade de recursos que os informantes podem } \\
\text { oferecer como alternativas para as pessoas fazerem escolhas } \\
\text { informadas); Sentir-se "apoiado" para ajudar as pessoas a } \\
\text { alcançar seus objetivos emergiu dos temas básicos de (a) } \\
\text { autossuporte (Uma combinação de conhecimento, experiência } \\
\text { de vida-trabalho e autocuidado) e (b) apoio de outros (Apoio } \\
\text { adicional foi identificado em relacionamentos formais e } \\
\text { informais). O sucesso na defesa de direitos foi descrito como } \\
\text { cuidar e descobrir como ajudar as pessoas a alcançarem todos } \\
\text { os "grandes e pequenos objetivos", incluindo estilo de vida, } \\
\text { escolhas culturais, espirituais, de higiene e higiene. A } \\
\text { compreensão emocional, o cuidado e o gerenciamento } \\
\text { descritos se concentraram em cuidar, informar e proteger as } \\
\text { coisas importantes para as pessoas. Isso revelou objetivos de } \\
\text { enfermagem moralmente justificáveis de confortar, melhorar } \\
\text { o enfrentamento, capacitar as pessoas e deixar os cuidadores } \\
\text { familiares com "as melhores memórias possíveis ... é } \\
\text { realmente uma experiência que permanece com eles por toda } \\
\text { a vida. Se for uma experiência muito boa, então é disso que }\end{array}$ \\
\hline
\end{tabular}




\begin{tabular}{|c|c|c|c|c|}
\hline & & & 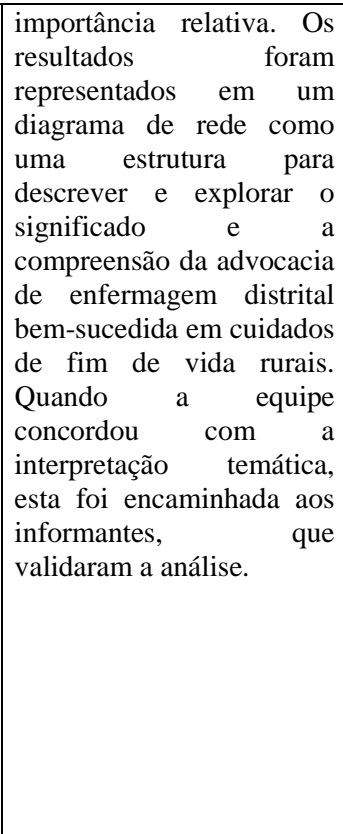 & $\begin{array}{l}\text { eles se lembram". A defesa de direitos foi vista como uma } \\
\text { ação essencial no gerenciamento bem-sucedido dos cuidados } \\
\text { no final da vida em circunstâncias difíceis de atendimento } \\
\text { domiciliar. Esta ação foi descrita como um continuum de } \\
\text { avaliação holística, comunicação eficaz e organização de } \\
\text { recursos para informar, apoiar e capacitar as pessoas para } \\
\text { gerenciar sua saúde. Os problemas que requerem esforço } \\
\text { adicional de advocacia foram identificados como mal- } \\
\text { entendidos sobre o papel da enfermagem distrital e o } \\
\text { significado dos cuidados paliativos, ideais conflitantes, } \\
\text { referências recebidas no ponto de crise e a falta de } \\
\text { comunicação, recursos, serviços e financiamento para as } \\
\text { necessidades de cuidados rurais. Todos os informantes } \\
\text { descreveram resultados "bons" do esforço de advocacia, mas } \\
\text { apontaram que tais resultados nem sempre eram alcançáveis. } \\
\text { Consequentemente, uma ação de advocacia bem-sucedida foi } \\
\text { definida como informar, perguntar, respeitar e pensar sobre a } \\
\text { pessoa e os cuidadores familiares e tentar apoiá-los nas metas } \\
\text { importantes para todos eles. Uma çãa de advocacia bem- } \\
\text { sucedida foi descrita como exigindo que os enfermeiros } \\
\text { distritais tenham uma atitude de "boa vontade". Estar disposto } \\
\text { permite o envolvimento e a energia emocional necessários } \\
\text { para cuidar autonomamente "de" e "sobre" as pessoas na } \\
\text { comunidade rural e defender seu bem-estar. }\end{array}$ \\
\hline 9 & $\begin{array}{l}\text { Testar } \\
\text { complementar os } \\
\text { resultados de uma } \\
\text { exploração narrativa } \\
\text { em profundidade de } \\
\text { como os } \\
\text { Enfermeiros } \\
\text { distritais defendem } \\
\text { com sucesso os } \\
\text { objetivos de final da } \\
\text { vida dos } \\
\text { australianos rurais. }\end{array}$ & $\begin{array}{l}\text { Foram enviados } 264 \text { e- } \\
\text { mails de convite, } \\
\text { buscando uma amostra } \\
\text { de autosseleção } \\
\text { intencional. Os convites } \\
\text { especificaram os } \\
\text { critérios de seleção de } \\
\text { enfermeiras generalistas } \\
\text { rurais registradas com } \\
\text { experiência ra de } \\
\text { advocacia bem-sucedida } \\
\text { para os objetivos de } \\
\text { pessoas que recebem } \\
\text { atendimento domiciliar. } \\
\text { Um link eletrônico para } \\
\text { a pesquisa anônima } \\
\text { disponível online na } \\
\text { Qualtrics foi incluído, } \\
\text { com uma cópia anexada } \\
\text { para visualização prévia } \\
\text { e devolução postal, se } \\
\text { preferir. Enfermeiros } \\
\text { que trabalham em áreas } \\
\text { urbanas e remotas foram } \\
\text { excluídos do estudo. }\end{array}$ & 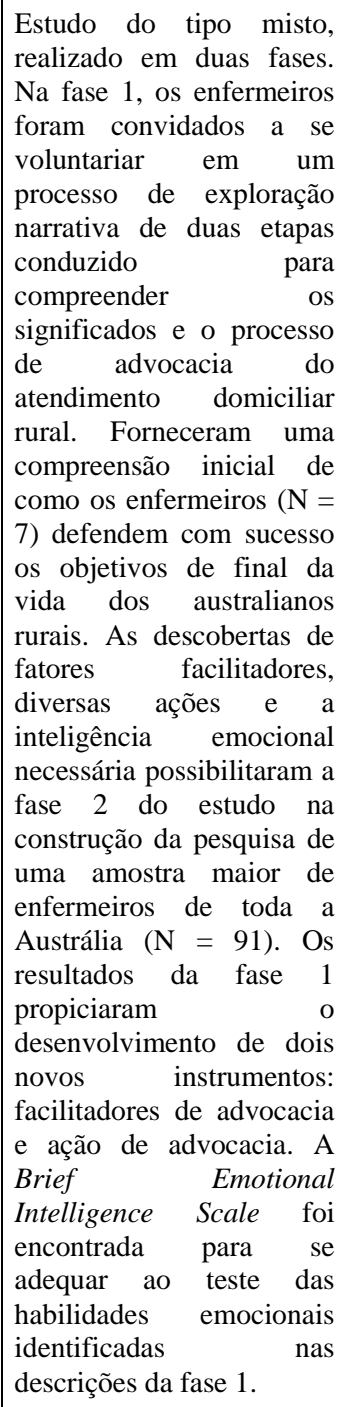 & 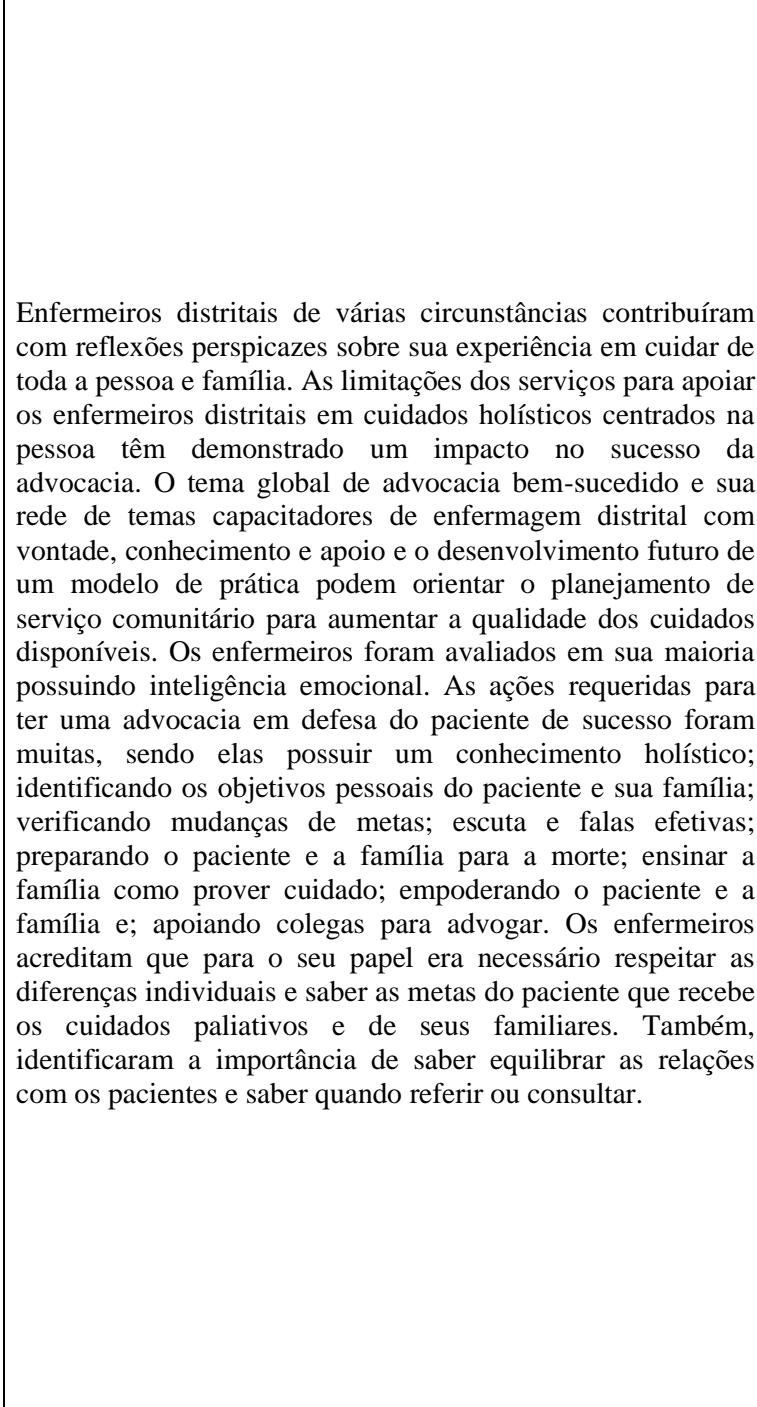 \\
\hline 10 & $\begin{array}{lr}\text { Descrever } & \text { a } \\
\text { advocacia } & \text { nos } \\
\text { cuidados anestésicos } \\
\text { durante a } & \text { fase } \\
\text { perioperatória } & \text { na }\end{array}$ & $\begin{array}{l}\text { Amostragem intencional } \\
\text { de enfermeiros de } \\
\text { ambos os sexos de dois } \\
\text { hospitais diferentes na } \\
\text { Suécia. O critério de }\end{array}$ & $\begin{array}{l}\text { Estudoráritorativo } \\
\text { exploratorio. Realizada } \\
\text { entrevista semiestruturada } \\
\text { iniciada com a pergunta } \\
\text { "O que ser o advogado do } \\
\end{array}$ & $\begin{array}{l}\text { Dos 20, } 16 \text { eram mulheres e quatro homens, com idades entre } \\
36 \text { e } 61 \text { anos (média de } 45 \text { anos) que tinham experiência de } \\
\text { trabalho em anestesia entre } 1,5 \text { e } 32 \text { anos (média de } 12,3 \\
\text { anos). }\end{array}$ \\
\hline
\end{tabular}




\begin{tabular}{|c|c|c|c|c|}
\hline & $\begin{array}{l}\text { perspectiva } \\
\text { enfermeiro } \\
\text { anestesista } \\
\text { registado. }\end{array}$ & 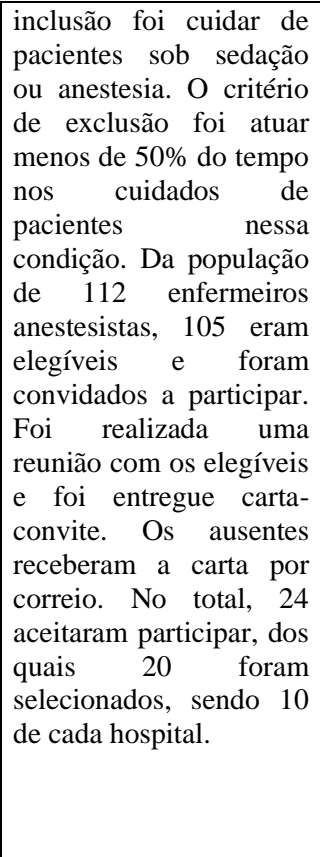 & $\begin{array}{l}\text { paciente significa para } \\
\text { você?"; seguido por "O } \\
\text { que você acha que } \\
\text { caracteriza a defesa da } \\
\text { anestesia pela } \\
\text { enfermagem?" e "O que } \\
\text { você acha que é o cerne da } \\
\text { defesa da anestesia pela } \\
\text { enfermagem?" Também } \\
\text { foram solicitados a narrar } \\
\text { uma situação em que } \\
\text { considerassem que agiram } \\
\text { como defensores do } \\
\text { paciente. As entrevistas } \\
\text { foram realizadas com } \\
\text { abordagem indutiva, o que } \\
\text { é adequado tendo em vista } \\
\text { as pesquisas limitadas } \\
\text { neste contexto. A análise } \\
\text { foi realizada por meio da } \\
\text { análise de conteúdo } \\
\text { qualitativa e resultou em } \\
\text { onze categorias, três } \\
\text { subtemas e um tema } \\
\text { principal. }\end{array}$ & $\begin{array}{l}\text { As categorias encontradas foram relacionadas a Prestar } \\
\text { cuidado digno compreendia [tratar o paciente com respeito], } \\
\text { [estabelecer confiança], [defender os direitos do paciente] e } \\
\text { [ser a autonomia vicária do paciente]. } \\
\text { Os enfermeiros anestesistas perceberam que forneciam } \\
\text { cuidado seguro [estando um passo à frente], [protegendo o } \\
\text { paciente de danos] e [informando o paciente]. } \\
\text { O significado de advocacia foi descrito pelos enfermeiros } \\
\text { como [obrigação], [estresse moral] e [coragem], mas também } \\
\text { [satisfação]. }\end{array}$ \\
\hline 11 & 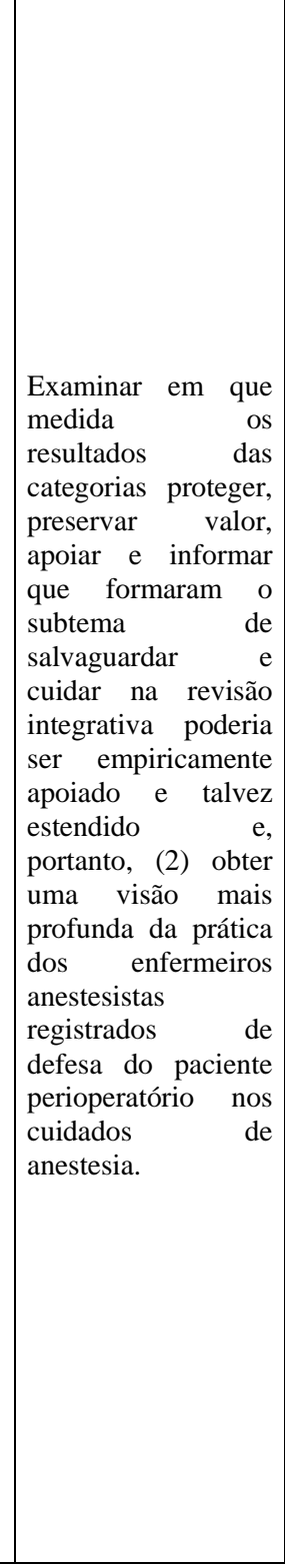 & $\begin{array}{l}\text { Oito enfermeiros (seis } \\
\text { mulheres e dois homens) } \\
\text { do departamento de } \\
\text { anestesia geral de um } \\
\text { hospital municipal na } \\
\text { Suécia concordaram em } \\
\text { participar e todos foram } \\
\text { incluídos. } \\
\text { Critério de inclusão: ser } \\
\text { um enfermeiro cuja } \\
\text { principal tarefa era } \\
\text { cuidar de pacientes no } \\
\text { período perioperatório. } \\
\text { O critério para } \\
\text { selecionar } \\
\text { procedimentos os } \\
\text { anestésicos rar para } \\
\text { observação era que o } \\
\text { enfermeiro anestesista } \\
\text { deveria realizar uma } \\
\text { anestesia geral durante } \\
\text { uma cirurgia planejada } \\
\text { não aguda em um } \\
\text { paciente com mais de } 18 \\
\text { anos de idade. Por } \\
\text { questões éticas, foram } \\
\text { excluídos os pacientes } \\
\text { submetidos a cirurgias } \\
\text { na região genital. }\end{array}$ & 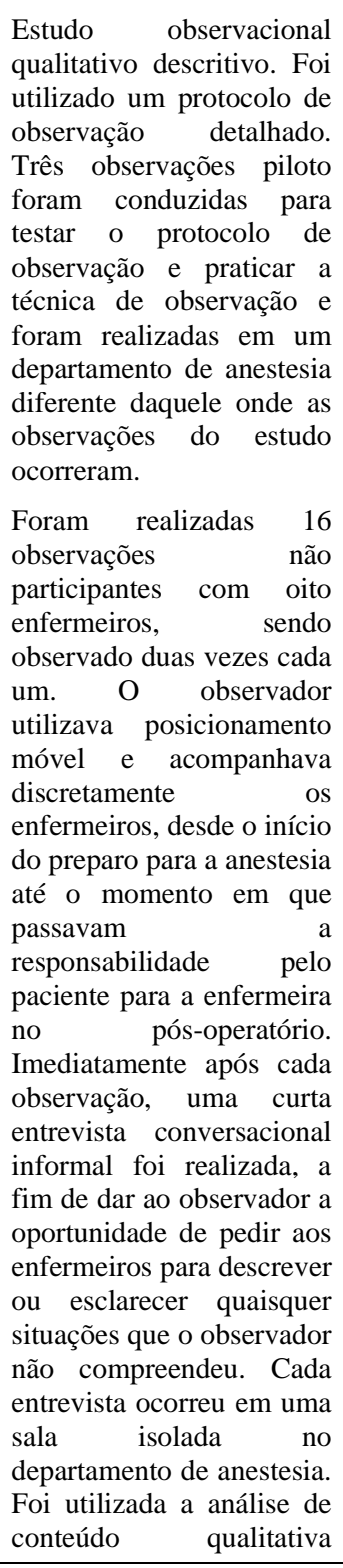 & 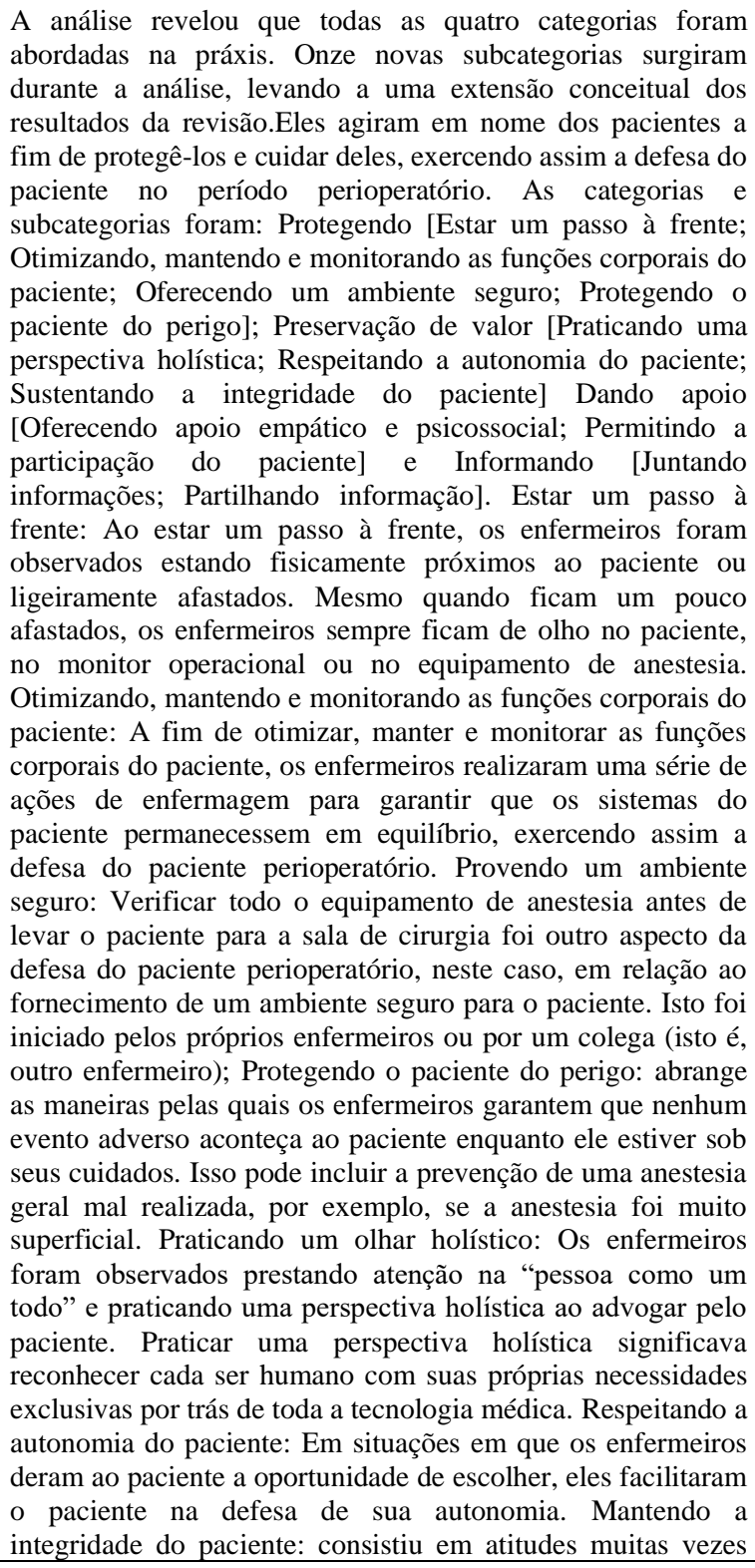 \\
\hline
\end{tabular}




\begin{tabular}{|c|c|c|c|c|}
\hline & & & dirigida. & $\begin{array}{l}\text { discretas, como cobri-lo de exposição desnecessária e } \\
\text { desviando o olhar durante uma conversa pessoal do paciente. } \\
\text { Oferecendo empatia e suporte psicossocial: foram observados } \\
\text { oferecendo suporte empático e psicossocial por meio de } \\
\text { comunicação verbal ou não verbal com o paciente. Juntando } \\
\text { informações: Os enfermeiros foram observados coletando } \\
\text { informações sobre o paciente e o estado físico do paciente, o } \\
\text { que incluiu a colaboração não apenas com os outros membros } \\
\text { da equipe, mas também com o paciente. Compartilhando } \\
\text { informações: Além de receberem informações sobre o } \\
\text { paciente, os enfermeiros foram observados compartilhando as } \\
\text { informações coletadas com outros membros da equipe, seja } \\
\text { oralmente, seja no prontuário. }\end{array}$ \\
\hline 12 & 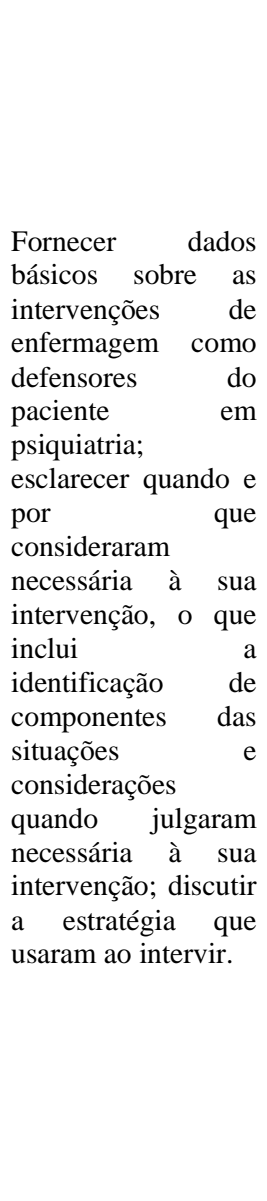 & \begin{tabular}{|lr} 
Critérios de & inclusão: \\
enfermeiros & com \\
experiência de & 5 anos ou \\
mais em & enfermagem \\
psiquiátrica; & seus \\
superiores & os \\
reconheceram romo & (a) \\
tendo alto nível & de \\
sensibilidade ética e (b) \\
fornecendo r cuidado \\
orientado ao paciente.
\end{tabular} & $\begin{array}{l}\text { Pesquisa qualitativa } \\
\text { descritiva. } \\
\text { realizadas entrevistas } \\
\text { semiestruturadas com as } \\
\text { seguintes questões: "Você } \\
\text { já experimentou algum } \\
\text { caso em que julgou que } \\
\text { precisava agir para } \\
\text { proteger os direitos } \\
\text { humanos ou promover o } \\
\text { bem-estar de um paciente? } \\
\text { Se sim, por favor, me fale } \\
\text { sobre isso. " Eles } \\
\text { forneceram a interpretação } \\
\text { da situação, as bases dos } \\
\text { julgamentos e as } \\
\text { estratégias planejadas para } \\
\text { serem utilizadas em } \\
\text { aproximadamente uma } \\
\text { hora. Os casos de } \\
\text { julgamento em relação à } \\
\text { advocacia foram extraídos } \\
\text { e os fatores ambientais } \\
\text { (incluindo os principais } \\
\text { participantes) e a base para } \\
\text { o julgamento foram } \\
\text { identificados para cada } \\
\text { caso. Em seguida, os casos } \\
\text { foram classificados em } \\
\text { grupos de acordo com os } \\
\text { fatores ambientais } \\
\text { relevantes e as bases de } \\
\text { julgamento. Por fim, o } \\
\text { tema foi identificado para } \\
\text { cada grupo. a }\end{array}$ & $\begin{array}{l}\text { Os } 21 \text { entrevistados eram } 6 \text { enfermeiras psiquiátricas do sexo } \\
\text { masculino e } 15 \text { do sexo feminino, com média de idade de } 44,5 \\
\text { anos (desvio padrão (DP) } 1 / 47,5 \text { anos) e tempo médio de } \\
\text { trabalho de } 14,1 \text { anos (DP } 1 / 46,3 \text { anos). Os dados consistiram } \\
\text { em } 45 \text { casos de Julgamento Clínico para Advocacia do } \\
\text { Paciente (CJPA). Esses casos envolveram } 45 \text { pacientes (26 } \\
\text { homens e } 19 \text { mulheres), consistindo em pacientes com } \\
\text { esquizofrenia (37), transtornos emocionais (4), deficiências de } \\
\text { desenvolvimento (3) e transtorno alimentar (1). Suas } \\
\text { residências incluíam hospital (33), casa (10) e outras } \\
\text { instalações de cuidado (2). Os dados incluíram (com } \\
\text { sobreposições) } 13 \text { casos de conflitos entre pacientes e suas } \\
\text { famílias, } 2 \text { casos de conflitos entre pacientes e residentes da } \\
\text { comunidade, } 6 \text { casos de conflitos entre pacientes e apoiadores } \\
\text { baseados na comunidade, } 8 \text { casos de conflitos entre pacientes } \\
\text { e profissionais de saúde, } 6 \text { casos relacionados ao isolamento / } \\
\text { restrições físicas (incluindo restrições comportamentais e } \\
\text { gestão de bens pessoais), } 3 \text { casos de problemas com o } \\
\text { recebimento de cuidados médicos em outros departamentos, } 8 \\
\text { casos de problemas com tratamento médico e } 7 \text { casos de } \\
\text { recusa de tratamento por parte dos pacientes. Tema } 1: \\
\text { Conflito com as pessoas ao redor impedindo os direitos dos } \\
\text { pacientes à vida e à segurança (13 casos). Tema } 2: \text { Políticas } \\
\text { dos profissionais de saúde que impedem a autodeterminação } \\
\text { dos pacientes (11 casos). Tema } 3: \text { Comportamento próprio ou } \\
\text { de familiares do paciente impedindo o tratamento adequado e } \\
\text { serviços de bem-estar (sete casos). Tema } 4: \text { Reconhecimento } \\
\text { próprio ou familiar impedindo a autoatualização do paciente } \\
\text { (seis casos). Tema 5: Tratamento médico ou cuidados de } \\
\text { enfermagem inadequados que impedem o direito dos } \\
\text { pacientes à liberdade (sete casos). Tema } 6 \text { : Conduta cruel } \\
\text { impedindo os direitos de propriedade dos pacientes (um caso). } \\
\text { a }\end{array}$ \\
\hline 13 & $\begin{array}{lr}\text { Conhecer como os } \\
\text { enfermeiros } \\
\text { exercendo } \\
\text { advocacia } \\
\text { paciente no contexto } \\
\text { hospitalar. }\end{array}$ & 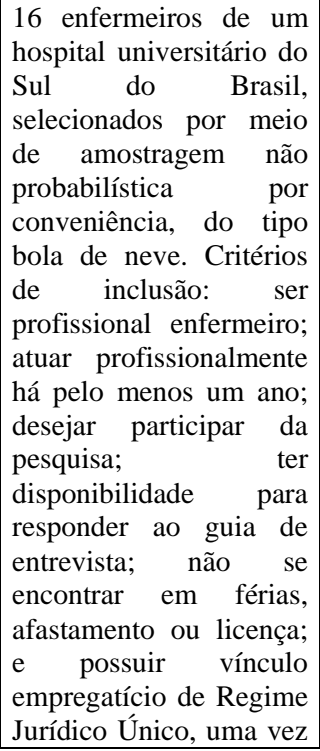 & $\begin{array}{lr}\text { Estudo } & \text { qualitativo } \\
\text { descritivo-exploratório. } \\
\text { Foram } & \text { realizadas } \\
\text { entrevistas } & \\
\text { semiestruturadas, } \\
\text { contendo } & \text { questões } \\
\text { fechadas, para a } \\
\text { caracterização } & \text { dos } \\
\text { sujeitos, e questões } \\
\text { abertas, enfocando } \\
\text { aspectos relacionados ao } \\
\text { exercício da advocacia do } \\
\text { paciente na enfermagem, } \\
\text { especialmente, no que se } \\
\text { referem às estratégias } \\
\text { utilizadas } \\
\text { enfermeiros para advogar } \\
\text { pelos pacientes, barreiras, } \\
\text { facilitadores e possíveis } \\
\text { implicações r desse } \\
\text { exercício. A análise dos } \\
\text { dados foi a partir da }\end{array}$ & $\begin{array}{l}\text { Na categoria 'a coragem de verdade: o exercício da advocacia } \\
\text { mediado pelo diálogo franco', foi possível evidenciar que a } \\
\text { advocacia do paciente é exercida pelos enfermeiros, } \\
\text { especialmente através do diálogo franco e verdadeiro, seja } \\
\text { com os pacientes, seja com profissionais de saúde, numa } \\
\text { tentativa de auxiliar os pacientes nas suas decisões e garantir a } \\
\text { qualidade do cuidado, mesmo com o risco de possíveis } \\
\text { rupturas em suas relações profissionais, principalmente } \\
\text { quando identificam que os pacientes não se mostram } \\
\text { suficientemente informados e esclarecidos sobre os cuidados } \\
\text { com sua saúde para exercerem sua autonomia. } \\
\text { Já na categoria 'Estratégias de resistência para o exercício da } \\
\text { advocacia do paciente', encontram-se as estratégias de } \\
\text { resistência adotadas pelos enfermeiros para exercer a } \\
\text { advocacia do paciente, especialmente, os caminhos de } \\
\text { enfrentamento utilizados diante das barreiras que se } \\
\text { apresentam ao exercício da advocacia. Ao utilizarem } \\
\text { estratégias e encontrarem espaços para resistir em seus } \\
\text { ambientes de trabalho, os enfermeiros pretendem fortalecer } \\
\text { seu exercício de poder, potencializando as ações em defesa } \\
\text { dos interesses do paciente. O exercício da autonomia e a }\end{array}$ \\
\hline
\end{tabular}




\begin{tabular}{|c|c|c|c|c|}
\hline & & $\begin{array}{l}\text { que se acredita que esses } \\
\text { enfermeiros têm maior } \\
\text { possibilidade de exercer } \\
\text { a advocacia do paciente } \\
\text { em seus ambientes de } \\
\text { trabalho. }\end{array}$ & análise textual discursiva. & $\begin{array}{l}\text { opção de persistir em advogar pelos pacientes foram } \\
\text { evidenciadas como importantes estratégias de resistência } \\
\text { utilizadas pelos enfermeiros, mesmo diante das barreiras que } \\
\text { possam dificultar ou impedir o exercício da advocacia. }\end{array}$ \\
\hline 14 & $\begin{array}{l}\text { Determinar } \\
\text { atividades as } \\
\text { relacionadas à } \\
\text { defesa de direitos } \\
\text { dos membros da } \\
\text { American Society } \\
\text { for Pain } \\
\text { Management } \\
\text { Nursing (ASPMN) }\end{array}$ & 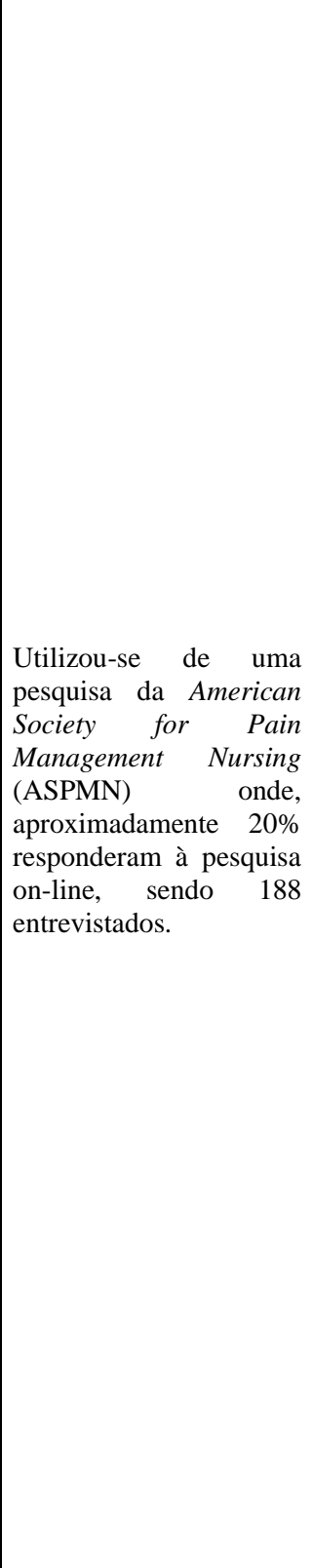 & 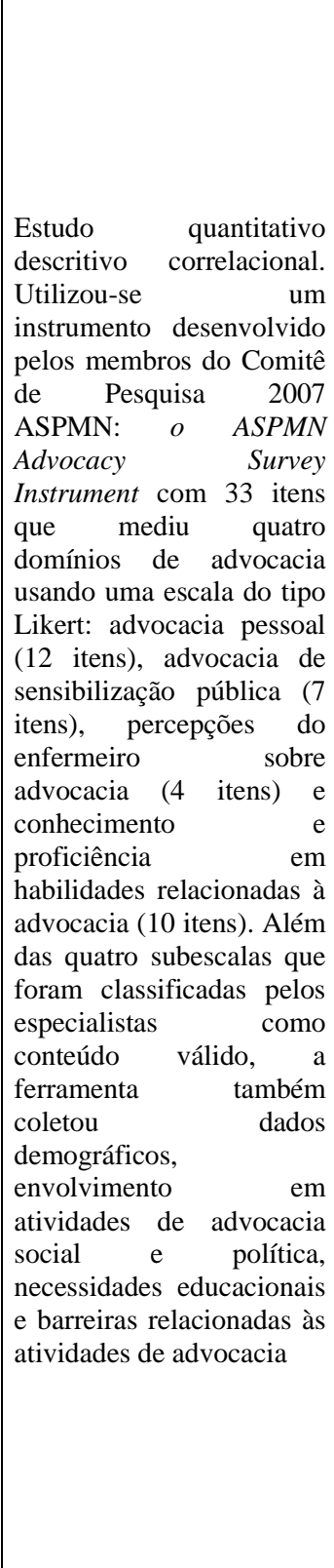 & 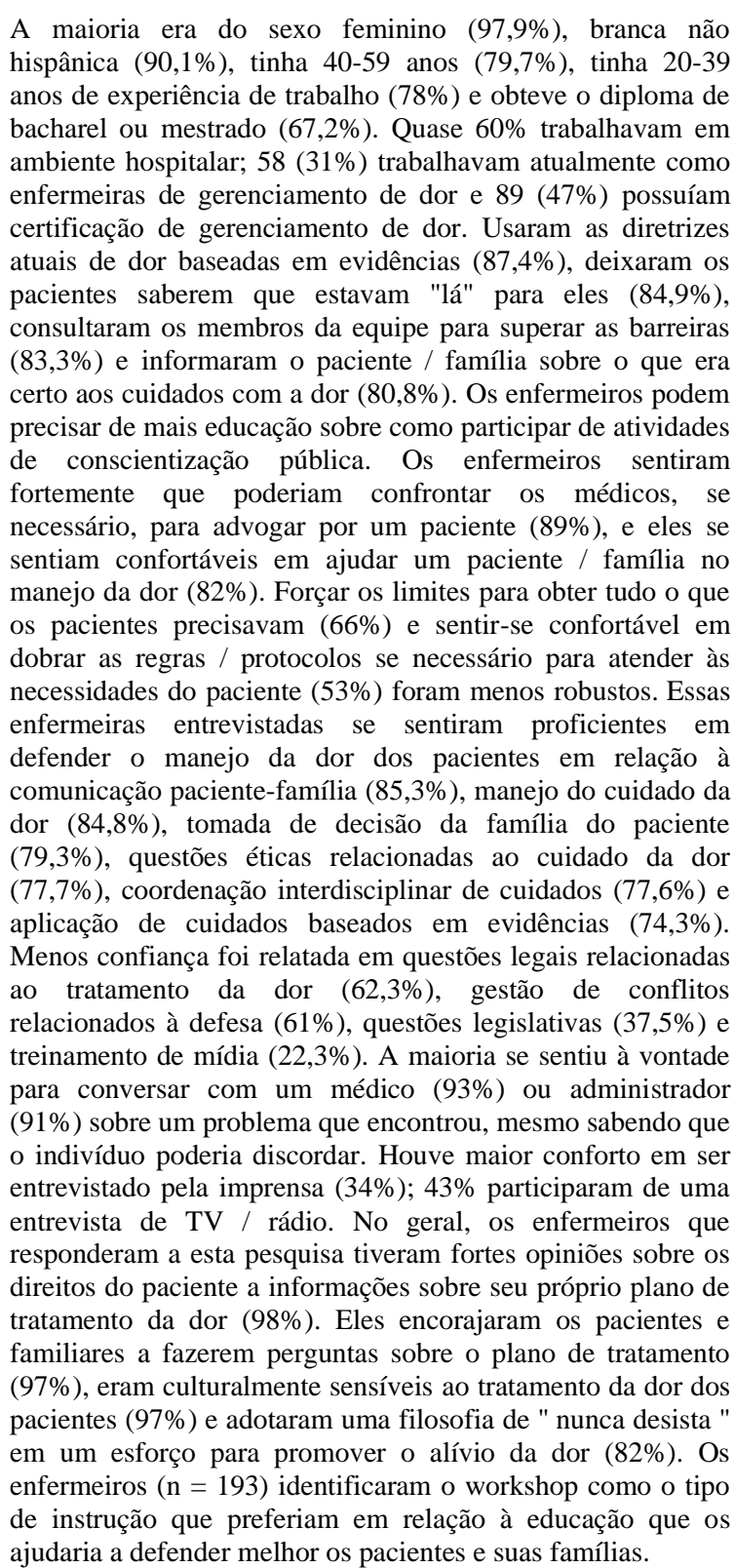 \\
\hline
\end{tabular}

Fonte: Autores.

Remetendo-se à pergunta norteadora do estudo, evidenciou-se que os enfermeiros advogaram em defesa do paciente com diversas ações e necessitando de características pessoais. Os artigos que compuseram a amostra do estudo podem ser sistematizados e apresentados a partir das seguintes categorias: Identificação de vulnerabilidades do direito do paciente e Comunicação com paciente, familiares e outros profissionais.

\section{Discussão}

As principais vulnerabilidades estavam relacionadas a idade dos pacientes (Andrade et al., 2013, 2015), atendimento inseguro ao paciente (Black, 2011), no fim de vida (Reed et al., 2018; Reed et al., 2017), no manejo da dor (Ware et al., 2011) 
e pacientes psiquiátricos (Toda et al., 2015).

A coleta de dados para a assistência de advocacia é evidenciada na puericultura como momento de olhar e escuta com a criança, mãe e família através de uma avaliação integral da saúde e seu meio de convívio, possibilitando a identificação das vulnerabilidades e o planejamento das condutas a serem tomadas (Andrade et al., 2013). Ainda na defesa da saúde da criança, utilizaram-se da VD como instrumento de coleta de dados ao reconhecimento de situações da criança e família em seu espaço social, cultural e outras demandas que não eram levadas até às consultas de enfermagem na ESF (Andrade et al., 2015).

Um estudo australiano com sete enfermeiros distritais evidenciou a defesa do paciente ao conhecimento sobre o paciente em seu domicílio e nas circunstâncias sociais em que ele está inserido. Também como ao conhecimento dos recursos de saúde dos quais ele pode usufruir e dos recursos que a comunidade tem a oferecer para ele e o paciente de modo com que possa advogar (Reed et al., 2017).

Outro estudo com 15 enfermeiros das ESF de um município no sul do Brasil evidenciou fatores ambientais e locais como parte da advocacia em saúde, ao reconhecer a comunidade que a unidade está inserida, como também sua população e seus grupos específicos permitem identificar suas vulnerabilidades (Figueira et al., 2018).

Os enfermeiros advogam pelo paciente ao avaliar que ele não possui informação ou pouco esclarecido sobre seus cuidados e direitos. Também, colhem informações sobre ele e seu estado físico através de um olhar holístico reconhecendo cada um dos pacientes com suas próprias necessidades exclusivas (Sundqvist, Nilsson, Holmefur \& Andérzen-Carlsson, 2018) através da identificação dos objetivos dos pacientes e seus familiares (Reed et al., 2018) e dos desejos dos pacientes (Hanks, 2010).

O diagnóstico de risco ou da própria violação do direito do paciente sucede à avaliação inicial pela coleta de dados. A identificação de vulnerabilidades, e, até mesmo da violação dos próprios direitos é abordado por Andrade et al. (2013, 2015) onde tanto na puericultura como na prática da VD é investigado as situações em que a criança em seu estado de dependência de ações de outros indivíduos necessita que os responsáveis estejam cumprindo seu papel pela criança. As vulnerabilidades das crianças são identificadas pela ausência dos pais no convívio e nas consultar por necessitarem do trabalho para sustentar a família. O abuso de álcool e outras drogas refere como um grande risco para a manutenção, uma vez que compromete a parceria dos pais com a assistência de saúde e o cuidado da criança. Também, ao depararem com situações em que a puérpera apresenta depressão pós-parto identificam uma situação de vulnerabilidade da criança, onde a mãe está menos suscetível aos cuidados da criança. Essas situações identificadas dos responsáveis pela criança tornam-se riscos ou até mesmo a violação dos direitos da criança.

Essas vulnerabilidades encontradas, em específico com relação à saúde da criança e sua família, são evidenciadas em outra literatura que refere às situações de exclusão e inserção em que eles são envolvidos, sendo em sua maioria classificados quanto à fatores sociais como pobreza e doenças (Oliveira et al., 2014).

Sabendo-se que a defesa do paciente é inerente à assistência de enfermagem, faz-se necessário da advocacia em saúde seja sistematizada seguindo o Processo de Enfermagem (PE) como método para orientar o cuidado do profissional de enfermagem. Esse, segundo a Resolução do Conselho Federal de Enfermagem (COFEN) nº 358/2009, é composto por cinco etapas, sendo elas, coleta de dados de enfermagem, diagnóstico de enfermagem, planejamento de enfermagem, implementação e avaliação de enfermagem (Resolução COFEN-358/2009).

A coleta de dados para a assistência de advocacia é evidenciada nas diversas situações da rotina do enfermeiro. Frente a coleta de informações, enfermeiros evidenciaram uma resistência da investigação do enfermeiro por parte dos familiares, em que ocultam algumas informações que compreendem que possam o comprometer. Esses comportamentos danosos às crianças e a falta de informação gera angústia aos enfermeiros, que para superar essa barreira necessitam ter uma abordagem delicada e cuidadosa, pois a falha nessa comunicação pode distanciar a relação do enfermeiro com a família (Andrade et al., 2015). 
Posteriormente, o enfermeiro desempenha as etapas de planejamento, implementação e avaliação de enfermagem por função da atuação do enfermeiro ao advogar em defesa da saúde do paciente.

A partir do diagnóstico das vulnerabilidades, do risco e da violação do direito do paciente, o enfermeiro planeja suas intervenções frente a particularidade da necessidade do paciente. Os estudos avaliados evidenciaram o planejamento de forma subjetiva, ao utilizar do reconhecimento e investigação do local de vivência e de suas particularidades de saúde para planejar estratégias comunitárias e individuais (Figueira et al., 2018).

No âmbito perioperatório, esse planejamento é elucidado pelos enfermeiros anestesista ao investigar integralmente cada paciente, identificando os possíveis riscos que ele poderia ter e planejando o material que será usado e possivelmente usado durante o procedimento e em casos de complicações (Sundqvist \& Carlsson, 2014). Também, em outro estudo os enfermeiros anestesistas ao estarem um passo à frente das situações refere ao estar sempre observando a situação do paciente, checando monitores operacionais ou os equipamentos de anestesia (Sundqvist, Nilsson, Holmefur \& Andrezén-Carlsson, 2018).

A implementação das ações planejadas foi evidenciada sendo realizadas pelos enfermeiros das mais diversas formas. Uma das atitudes tomadas pelos enfermeiros é de empoderamento do paciente (Figueira et al., 2018; Reed et al., 2018), em vista que o profissional defende-os ao mantê-los informados sobre suas condições de saúde, tratamento e orientando-os sobre seus direitos (Luz et al., 2019; Negarandeh \& Nayeri, 2012). Também, em um estudo referente à advocacia em saúde sobre o manejo da dor, $80,8 \%$ dos enfermeiros defenderam o paciente ao informá-lo e a sua família sobre o que está certo aos cuidados da dor (Ware et al., 2011).

A comunicação torna-se um grande componente da advocacia tanto com o paciente e sua família como também com outros profissionais. O enfermeiro para defender o paciente trabalha como mediador das relações e comunicações ao encaminhar as necessidades do paciente para outros profissionais (Andrade et al., 2013), assim como para atualizá-lo e compartilhar informações que sejam relevantes para caracterização do paciente e sua condição de saúde integralmente (Sundqvist, Nilsson, Holmefur \& Anderzén-Carlsson, et al., 2018). No estudo de Ware et al. (2011), 83,3\% dos enfermeiros consultaram membros da equipe de saúde para superar barreiras referentes a defesa do paciente.

Além disso, parte da defesa do paciente o questionamento de condutas de outros profissionais, uma vez que os mesmos possam estar atuando sem perícia, de forma imprudente ou negligente (Hanks, 2010a). Em um estudo enfermeiros com experiência em psiquiatria necessitaram intervir na relação médico-paciente ao identificar situações em que a conduta de médicos impediam a tomada de decisão e até mesmo a liberdade do paciente (Toda et al., 2015).

O diálogo franco e corajoso com a própria equipe de saúde para exercer a advocacia do paciente também se mostrou como um exercício de poder, seja na ênfase e na priorização de ações benéficas ao paciente, ou no enfrentamento de situações reconhecidas como moralmente inadequadas. Ao manifestarem claramente suas crenças em relação aos cuidados que prestam e aos que são prestados aos pacientes, ou mesmo, ao aconselharem ou criticarem um membro da equipe de saúde sobre sua forma de agir, os enfermeiros advogam pelos interesses dos pacientes, optando por exercer poder e não permanecer indiferentes e coniventes com o que presenciaram. Reconhecem se exercício de poder e, consequentemente, a possibilidade de desencadear um conflito em suas relações profissionais, com o risco de desconforto e rupturas. Ao utilizarem o conhecimento como estratégia para advogar pelos pacientes, os enfermeiros fortalecem o exercício de sua autonomia e o exercício de poder, desafiando comumente, decisões baseadas na autoridade médica. Quando essas situações reconhecidas como inadequadas não são resolvidas por meio do diálogo franco com a equipe de saúde, os enfermeiros afirmam advogar pelos pacientes, principalmente através da denúncia. Ao romperem com tais situações, os enfermeiros referem sentir-se aliviados, apesar dos conflitos e do aparente desgaste provocado (Tomaschewski Barlem et al., 2016).

As situações inadequadas de cuidado que ferem o direito do paciente necessitam ser reportadas, no entanto, evidencia- 
se muitas barreiras nesta ação. No estudo de Black et al. (2011), mais de um terço dos enfermeiros sabiam de uma situação de atendimento inseguro, mas não reportaram por medo de retaliação (44\%) ou por não acreditarem a ação traria consequências positivas para o paciente (38\%). Ainda, os enfermeiros que conheciam ou sabiam de algum profissional que sofreu retaliação após uma denúncia tinham duas vezes menor probabilidade de relatar uma violação do direito do paciente.

Esta relação conflituosa também se relaciona à questões culturais em que observa-se uma hierarquização inválida do médico acima dos demais profissionais de saúde (Luz et al., 2019). Barreiras na advocacia em saúde pelo enfermeiro foi evidenciada em outro artigo, onde enfermeiras sauditas relatam que por conta da cultura e religião do país em que vivem, há distinção entre gêneros, de modo que às desvalorize ao questionar condutas médicas, receberem retaliações e até mesmo dificuldade de defender pacientes masculinos por não poderem estarem próximas de outros homens que não sejam da família delas (Mortell, 2018).

Para o enfrentamento de situações de conflito e questionamento da conduta de outros profissionais, o enfermeiro sente-se mais seguro e autônomo ao embasar seus questionamentos em evidências, diretrizes e protocolos, no entanto a preocupação com os danos causados aos pacientes como resultado de erros médicos levanta a questão sobre até que ponto os enfermeiros sentem-se confiantes para expressar suas preocupações sobre a prática médica (Churchman \& Doherty, 2010).

Outras atitudes que partem do enfermeiro para uma característica pessoal foram evidenciadas como facilitadores e necessárias para defender os pacientes nas diversas etapas do processo. Para defender o paciente, o enfermeiro precisou estar disposto a investir no cuidado centrado no paciente ao seu envolvimento pessoal e profissional nas experiências dos pacientes e de sua rede de apoio. Também, necessitaram de autossuporte advindo do seu conhecimento e experiência profissional e apoio de outros profissionais, paciente e de pessoas do seu próprio convívio para manter-se firmes ao advogar pelo paciente (Reed et al., 2017).

Os enfermeiros acreditavam que, para agir como defensor, o paciente precisava confiar neles. O enfermeiro costuma ser a primeira pessoa que o paciente encontra antes de ir para a sala de cirurgia e, portanto, era importante estabelecer confiança nesse primeiro contato por comunicação verbal e não verbal. Verbalmente, quando o enfermeiro se apresenta por nome e cargo, garantindo ao paciente que ele ou outro colega zelaria e certificaria-se de que o paciente estaria seguro durante a anestesia. Não verbalmente, quando o enfermeiro olhava nos olhos do paciente e segurando sua mão indicando que está presente pelo paciente (Sundqvist \& Carlsson, 2014).

A ações de advocacia em saúde realizada pelos enfermeiros pressupõem uma melhora na condição de vulnerabilidade e manutenção do respeito aos seus direitos. Estudos elucidaram a partir das ações de advocacia tomadas pelos enfermeiros resultados positivos sobre suas atitudes. No estudo de Andrade et al. (2013), as consultas de puericultura nas suas ações de orientar e encaminhar crianças que apresentavam situações de vulnerabilidade quanto à alimentação e baixo desenvolvimento trouxeram resultados positivos ao apresentar que, respectivamente, as crianças tiveram um aumento do peso e estava sendo acompanhada pelo pediatra. Já no estudo de Toda et al. (2015), os enfermeiros apresentaram resultados positivos ao enfrentamento de condutas médicas que impediam a liberdade do paciente e de ensinamento de pacientes que possuíam dificuldades na socialização, permitindo-os que voltassem para seus convívios sociais.

Evidencia-se por parte dos enfermeiros uma avaliação holística contínua do paciente assim como a necessidade de verificação de mudanças nas suas metas para a reformulação das suas vulnerabilidades e planejamento de suas ações frente aos direitos do paciente (Reed et al., 2018).

\section{Considerações Finais}

Este estudo forneceu uma revisão dos artigos originais que referem como o enfermeiro esteve atuando pelo paciente frente a advocacia em saúde. Apesar de a advocacia em saúde possuir diversas definições, ser embasada de uma prática 
subjetiva, foi possível analisar o conjunto de ações que a possam caracterizar e explicar como a defesa do paciente é exercida a partir da prática.

Estabelecendo por etapas, o enfermeiro tem advogado pelo paciente, primeiramente, na coleta de informações e identificação de suas vulnerabilidades, onde através de ações como avaliar, identificar, investigar e observar, o profissional pôde definir em quais situações o direito do paciente se apresentou em risco ou violação, em seus âmbitos culturais, sociais, financeiro e de saúde. Os estudos abordados nesta RI trouxeram de forma específica os grupos de crianças, pacientes anestesiados, em fim de vida e com transtorno mentais, grupos estes que apresentam barreiras para se autodefender.

A comunicação torna-se fundamental para o exercício da advocacia em saúde pelo enfermeiro, seja com o paciente, família ou outros profissionais. Parte dessa ação outras como orientar, encaminhar, informar, questionar e relatar. É imprescindível que tanto o enfermeiro como o paciente tenham consciência dos direitos do paciente, e, por parte do enfermeiro utilizar da comunicação para ser o intermédio da manutenção do respeito a esses direitos. Embora enfrente diversas barreiras, os enfermeiros apresentaram de o dever ético do enfermeiro assegurar e proteger o paciente e seus direitos, sempre buscando avaliar mudanças nos seus desejos.

Como limitação da presente RI, destaca-se a própria abordagem/desenho dos estudos encontrados. Ressalta-se que nenhum dos estudos propuseram como objetivo uma abordagem das ações de advocacia pelo enfermeiro como processo de enfermagem. Pela própria subjetividade do tema, recomenda-se a realização de novas investigações com outras abordagens metodológicas que contribuam para o acréscimo das ações em advocacia em saúde realizada pelos enfermeiros, a fim de fortalecer uma definição completa e clara sobre advocacia e elucidar como os enfermeiros atual frente à defesa do paciente.

\section{Referências}

Andrade, R. D., Santos, J. S., Maia, M. A. C., Silva, M. A. I., Veríssimo, M. L. Ó. R., \& Mello, D. F. (2015). Home visit: Care technology used by nurses to advocate for child's health. Texto \& Contexto - Enfermagem, 24(4), 1130-1136. https://doi.org/10.1590/0104-0707201500000120015

Andrade, R. D., Santos, J. S., Pina, J. C., Silva, M. A. I., \& Mello, D. F. (2013). The child care as time defense of the right to health of children. Ciência, Cuidado e Saúde, 12(4), 719-727.

Barlem, E. L. D., Lunardi, V. L., Lunardi, G. L., Tomaschewski-Barlem, J. G., \& Silveira, R. S. (2013). Moral distress in everyday nursing: Hidden traces of power and resistance. Revista Latino-Americana de Enfermagem, 21(1), 293-299. https://doi.org/10.1590/S0104-11692013000100002

Black, L. M. (2011). Tragedy into Policy: A Quantitative Study of Nurses' Attitudes Toward Patient Advocacy Activities. American Journal of Nursing, $111(6), 26-37$.

Bu, X., \& Jezewski, M. A. (2007). Developing a mid-range theory of patient advocacy through concept analysis. Journal of Advanced Nursing, 57(1), 101110. https://doi.org/10.1111/j.1365-2648.2006.04096.x

Churchman, J. J., \& Doherty, C. (2010). Nurses' view on challenging doctors' practice in an acute hospital. Nursing Standard, $24(40)$, 42-47.

Cole, C., Wellard, S., \& Mummery, J. (2014). Problematising autonomy and advocacy in nursing. Nursing Ethics, 21(5), 576-582. https://doi.org/10.1177/0969733013511362

Conselho Federal de Enfermagem. (2009). Resolução COFEN-358/2009. Dispõe sobre a Sistematização da Assistência de Enfermagem e a implementação do Processo de Enfermagem em ambientes, públicos ou privados, em que ocorre o cuidado profissional de Enfermagem, e dá outras providências. http://www.cofen.gov.br/resoluo-cofen-3582009_4384.html

Figueira, A. B., Barlem, E. L. D., Tomaschewski-Barlem, J. G., Dalmolin, G. L., Amarijo, C. L., \& Ferreira, A. G. (2018). Ações de advocacia em saúde e empoderamento do usuário por enfermeiros da Estratégia Saúde da Família. Revista da Escola de Enfermagem da USP, 52, e03337. https://doi.org/10.1590/s1980-220x2017021603337

Hamric, A. B., Borchers, C. T., \& Epstein, E. G. (2012). Development and Testing of an Instrument to Measure Moral Distress in Healthcare Professionals. AJOB Primary Research, 3(2), 1-9. https://doi.org/10.1080/21507716.2011.652337

Hanks, R. G. (2008). The lived experience of nursing advocacy. Nursing Ethics, 15(4), 468-477. https://doi.org/10.1177/0969733008090518

Hanks, R. G. (2010a). Development and testing of an instrument to measure protective nursing advocacy. Nursing Ethics, 17(2), $255-267$.

Hanks, R. G. (2010b). The Medical Surgical Nurse Perspective of Advocate Role. Nursing Forum, 45(2), 97-107.

Hanks, R. G., Starnes-Ott, K., \& Stafford, L. (2018). Patient Advocacy at the APRN Level: A Direction for the Future. Nursing Forum, 53(1), 5-11. https://doi.org/10.1111/nuf.12209 
Knitzer, J. E. (1976). Child advocacy: A perspective. The American Journal of Orthopsychiatry, 46(2), 200-216. https://doi.org/10.1111/j.19390025.1976.tb00921.x

Luz, K. R. da, Vargas, M. A. O., Peter, E., Barlem, E., Viana, R. A. P. P., \& Ventura, C. A. A. (2019). Advocacy in intensive care and hospitalization by court order: What are the perspectives of nurses? Texto \& Contexto - Enfermagem, 28, e20180157. https://doi.org/10.1590/1980-265x-tce-2018-0157

Melnyk, B. M., \& Fineout-Overholt, E. (2019). Evidence-based practice in nursing and healthcare: A guide to best practice. (4a ed). Wolters Kluwer.

Mendes, K. D. S, Silveira, R. C. C. P, Galvão, C. M. (2008). Revisão integrativa: método de pesquisa para a incorporação de evidências na saúde e na enfermagem. Texto \& Contexto Enfermagem, 17(4), 758-764.I.

Mortell, M. (2018). A patient advocacy dilemma: Is it theory...practice... Or an ethics gap? A qualitative analysis. Singapore Nursing Journal, 45(3), 17-26.

Negarandeh, R., \& Nayeri, N. D. (2012). Patient advocacy practice among Iranian nurses. Indian Journal of Medical Ethics, 3, Article 3. https://doi.org/10.20529/IJME.2012.063

Negarandeh, R., Oskouie, F., Ahmadi, F., Nikravesh, M., \& Hallberg, I. R. (2006). Patient advocacy: Barriers and facilitators. BMC Nursing, 5(1), 3. https://doi.org/10.1186/1472-6955-5-3

Neves, F. B. das, Vargas, M. A. de O., Zilli, F., Trentin, D., Huhn, A., \& Brehmer, L. C. F. (2020). Advocacia em saúde na enfermagem oncológica: Revisão integrativa da literatura. Escola Anna Nery, 25. https://doi.org/10.1590/2177-9465-EAN-2020-0106

Ouzzani, M., Hammady, H., Fedorowicz, Z., \& Elmagarmid, A. (2016). Rayyan—A web and mobile app for systematic reviews. Systematic Reviews, 5(1), 210. https://doi.org/10.1186/s13643-016-0384-4

Pinto, A. G. A., Jorge, M. S. B., Marinho, M. N. A. S. B., Vidal, E. C. F., Aquino, P. S. \& Vidal, E. C. F. (2017). Experiences in the Family Health Strategy: Demands and vulnerabilities in the territory. Revista Brasileira de Enfermagem, 70(5), 920-927. https://doi.org/10.1590/0034-7167-2015-0033

Polit, D. F., \& Beck, C. T. (2018). Fundamentos de Pesquisa em Enfermagem: Avaliação de Evidências para a Prática da Enfermagem (9a ed.). Artmed.

Reed, F., Fitzgerald, L., \& Bish, M. (2018). Advocating for end-of-life choice at home: A survey of rural Australian nurses. Rural and Remote Health. https://doi.org/10.22605/RRH4322

Reed, F. M., Fitzgerald, L., \& Bish, M. R. (2017). Rural District Nursing Experiences of Successful Advocacy for Person-Centered End-of-Life Choice. Journal of Holistic Nursing, 35(2), 151-164. https://doi.org/10.1177/0898010116646643

Santos, C. M. da C., Pimenta, C. A. M., \& Nobre, M. R. C. (2007). The PICO strategy for the research question construction and evidence search. Revista Latino-Americana de Enfermagem, 15(3), 508-511. https://doi.org/10.1590/S0104-11692007000300023

Simmonds, A. H. (2008). Autonomy and advocacy in perinatal nursing practice. Nursing Ethics, 15(3), 360-370. https://doi.org/10.1177/0969733007088360

Soares, C. B., Hoga, L. A. K., Peduzzi, M., Sangaleti, C., Yonekura, T., \& Silva, D. R. A. D. (2014). Revisão integrativa: conceitos e métodos utilizados na enfermagem. Revista da Escola de Enfermagem da USP, 48, 335-345. https://doi.org/10.1590/S0080-6234201400002000020

Spence, K. (2011). Ethical advocacy based on caring: A model for neonatal and paediatric nurses. Journal of Paediatrics and Child Health, 47(9), 642-645. https://doi.org/10.1111/j.1440-1754.2011.02178.x

Sundqvist, A.-S., \& Carlsson, A. A. (2014). Holding the patient's life in my hands: Swedish registered nurse anaesthetists' perspective of advocacy. Scandinavian Journal of Caring Sciences, 28(2), 281-288. https://doi.org/10.1111/scs.12057

Sundqvist, A.-S., Nilsson, U., Holmefur, M., \& Anderzén-Carlsson, A. (2018). Promoting person-centred care in the perioperative setting through patient advocacy: An observational study. Journal of Clinical Nursing, 27(11-12), 2403-2415. https://doi.org/10.1111/jocn.14181

Toda, Y., Sakamoto, M., Tagaya, A., Takahashi, M., \& Davis, A. J. (2015). Patient advocacy: Japanese psychiatric nurses recognizing necessity for intervention. Nursing Ethics, 22(7), 765-777. https://doi.org/10.1177/0969733014547971

Tomaschewisk Barlem, J. G., Lunardi, V. L., Devos Barlem, E. L., Ramos, A. M., Silveira, R. S. da, \& Vargas, M. A. O. (2016). How have nurses practiced patient advocacy in the hospital context? - A foucaultian perspective. Texto \& Contexto - Enfermagem, 25(1), 1-9.

Tomaschewski-Barlem, J. G., Lunardi, V. L., Barlem, E. L. D., Silveira, R. S., Dalmolin, G. L., \& Ramos, A. M. (2015). Cross-cultural adaptation and validation of the Protective Nursing Advocacy Scale for Brazilian nurses. Revista Latino-Americana de Enfermagem, 23(4), 669-676. https://doi.org/10.1590/0104-1169.0214.2602

Vaartio, H., Leino-Kilpi, H., Suominen, T., \& Puukka, P. (2009). Nursing Advocacy in Procedural Pain Care. Nursing Ethics, 16(3), 340-362. https://doi.org/10.1177/0969733009097992

Ware, L. J., Bruckenthal, P., Davis, G. C., \& O’Conner-Von, S. K. (2011). Factors That Influence Patient Advocacy by Pain Management Nurses: Results of the American Society for Pain Management Nursing Survey. Pain Management Nursing, 12(1), 25-32. https://doi.org/10.1016/j.pmn.2009.12.001

Whittemore, R., \& Knafl, K. (2005). The integrative review: Updated methodology. Journal of Advanced Nursing, 52(5), 546-553. https://doi.org/10.1111/j.1365-2648.2005.03621.x 